\title{
Thyroid function and the risk of fibrosis of the liver, heart and lung in humans: A systematic review and meta-analysis
} \\ Arjola Bano MD PhD ${ }^{1,2,3,4}$, Layal Chaker MD PhD², Taulant Muka MD PhD³, Francesco U. S. \\ Mattace-Raso MD PhD ${ }^{5}$, Lia Bally MD PhD ${ }^{6}$, Oscar H. Franco MD PhD ${ }^{3}$, Robin P. Peeters MD \\ $\mathrm{PhD}^{2}$, Salman Razvi MD PhD ${ }^{1,7}$ \\ ${ }^{1}$ Institute of Genetic Medicine, Newcastle University, Newcastle upon Tyne, United \\ Kingdom \\ ${ }^{2}$ Department of Internal Medicine, Department of Epidemiology, and Academic Center for \\ Thyroid Diseases, Erasmus Medical Center, Rotterdam, the Netherlands \\ ${ }^{3}$ Institute of Social and Preventive Medicine (ISPM), University of Bern, Bern, Switzerland \\ ${ }^{4}$ Department of Cardiology, Inselspital, Bern University Hospital, University of Bern, Bern, \\ Switzerland \\ ${ }^{5}$ Section of Geriatric Medicine, Erasmus Medical Center, Rotterdam, the Netherlands \\ ${ }^{6}$ Department of Diabetes, Endocrinology, Clinical Nutrition and Metabolism, Bern \\ University Hospital, Bern, Switzerland \\ ${ }^{7}$ Queen Elizabeth Hospital, Gateshead Health NHS Foundation Trust, Gateshead, United \\ Kingdom \\ Emails \\ Arjola Bano: arjola.bano@ispm.unibe.ch \\ Layal Chaker: I.chaker@erasmusmc.nl \\ Taulant Muka: taulant.muka@ispm.unibe.ch \\ Francesco U. S. Mattace-Raso: f.mattaceraso@erasmusmc.nl \\ Lia Bally: Lia.Bally@insel.ch \\ Oscar H. Franco: oscar.franco@ispm.unibe.ch \\ Robin P. Peeters: r.peeters@erasmusmc.nl \\ Salman Razvi: salman.razvi@newcastle.ac.uk \\ Short title \\ Thyroid function and fibrosis \\ Keywords
}

thyroid function, fibrosis, liver, heart, lung 


\section{ABSTRACT}

\section{Background}

Fibrotic diseases have an unclear etiology and poor prognosis. Fluctuations in thyroid function may play a role in the development of fibrosis, but evidence is fragmented and inconclusive. This systematic review and meta-analysis aimed to investigate the association of thyroid function with fibrotic diseases of the liver, heart, and lung, in humans.

\section{Methods}

We searched Pubmed, Medline Ovid, Embase Ovid, and Web-of-Science for studies published from inception to 14 June 2019, to identify observational studies that investigated the association of thyroid function with fibrosis of the liver, heart, and lung, in humans. Study quality was evaluated by Newcastle-Ottawa Scale. The Mantel-Haenszel method was used to pool the odds ratios (ORs) of studies investigating the association of hypothyroidism with liver fibrosis.

\section{Results}

Out of 2196 identified articles, 18 studies were included in the systematic review, of which 11 studies reported on liver fibrosis, 4 on myocardial fibrosis, and 3 on pulmonary fibrosis. The population sample size ranged from 36 to 7259 subjects, with median mean age 51 years (range, 36-69) and median percentage of women 53 (range, 17-100). The risk of bias of studies was low to moderate to high. Higher serum thyrotropin and lower thyroid hormone levels were generally associated with higher likelihood of fibrosis. Compared to euthyroidism, overt and subclinical hypothyroidism were associated with a higher likelihood of fibrosis in the liver ( 6 of 7 studies), heart ( 3 of 3 studies), and lung ( 3 of 3 studies). Based on the results of the 7 studies included in the meta-analysis, overt and subclinical hypothyroidism were associated with an increased risk of liver fibrosis (pooled OR, 2.81; 95\% confidence interval [Cl], 1.74-4.53; heterogeneity, $I^{2} 31.4 \%$; pooled OR, 2.12; $\mathrm{Cl}, 1.45-3.12$, heterogeneity, $I^{2} 0 \%$ respectively), without evidence of publication bias. 


\section{Conclusions}

This study suggests that low thyroid function is associated with increased likelihood of

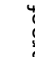
chronic fibrotic diseases of the liver, heart, and lung. However, the evidence is mainly $\stackrel{n}{\underline{\underline{E}}}$ based on cross-sectional data. Prospective studies and randomized clinical trials are

$$
\text { 芒 }
$$
needed to investigate the potential efficacy of thyroid hormone and its analogues on the occurrence and progression of fibrosis. 


\section{INTRODUCTION}

Fibrotic diseases, including liver cirrhosis, hypertrophic cardiomyopathy, and idiopathic pulmonary fibrosis, represent a significant cause of disability and mortality (1-4). The development of fibrosis is attributable to a maladaptive response characterized by the accumulation of extracellular matrix proteins such as collagen and fibronectin (5). Fibrotic elements progressively remodel and destroy the normal tissue architecture, ultimately resulting in organ failure. Hence, nonalcoholic steatohepatitis can progress to decompensated cirrhosis (6); myocardial fibrosis leads to ventricular diastolic dysfunction (7); whereas pulmonary fibrosis contributes to a decline in the lung function (8).

To date, the prognosis of fibrotic diseases remains poor, owing to the poor understanding of its pathogenesis and the lack of effective therapeutic options. Therefore, current research is focused on the identification of novel determinants of fibrosis, which could be further translated into the development of effective treatments (9-11). Among other factors, hypothyroidism has been implicated in the etiology of fibrosis (12-15). Pronounced hypothyroidism is typically characterized by an increased production of mucopolysaccharides, resulting in interstitial fibrosis and extracellular water retention, also known as myxedema (16). Yet, the exact role of thyroid hormones in the development of fibrosis remains unclear as well as controversial. A number of animal studies have reported profibrotic effects of hypothyroidism (13, 17-21); and beneficial effects of thyroid hormone supplementation on fibrosis of the liver $(22,23)$, heart (24-26), and lung (27). In contrast, other animal studies have observed an attenuation of fibrosis in experimental hypothyroidism $(28,29)$, and have shown profibrotic effects of thyroid hormone administration (30-34). Similar to animal studies, the results of epidemiological studies are also inconsistent. Some studies suggest a link between thyroid function and the risk of fibrosis of the liver, heart and lung $(12,14,15)$, whereas others report no such association $(35,36)$.

To date, there is a critical lack of literature synthesis concerning the impact of thyroid function on the occurrence and progression of organ fibrosis. Therefore, we aimed to summarize the current evidence regarding the association of thyroid function with fibrosis of the liver, heart and lung in humans. 


\section{MATERIALS AND METHODS}

\section{Data sources and search strategy}

This systematic review was conducted in accordance with the Preferred Reporting Items for Systematic Reviews and Meta-analyses (PRISMA) guidelines for transparent reporting (37). The checklist is provided in Appendix 1. Four electronic databases, including Pubmed, Medline Ovid, Embase Ovid, and Web-of-Science were searched without language restrictions from inception to 14 June 2019, with the help of expert librarians. From the date of the last search, we received monthly updates by the medical library in order to avoid missing new relevant references. The computer-based searches combined terms related to: (I) thyroid function (e.g., thyroid gland, thyroid disease, thyroid function, thyroid hormone, thyrotropin, thyroxine, triiodothyronine, thyronine, hyperthyroidism, thyrotoxicosis, Graves', hypothyroidism, Hashimoto, myxedema, deiodinase); (II) fibrosis of the liver, heart, and lung (e.g., liver fibrosis, nonalcoholic steatohepatitis, lung fibrosis, fibrosing alveolitis, fibrosing interstitial pneumonia, heart fibrosis); and (III) article type (i.e., Editorials, letters to the Editor, erratum, conference papers were excluded). Details of the search strategy are provided in Appendix 2.

\section{Study selection and data extraction}

The studies that fulfilled the following criteria were eligible: (I) Observational studies, including cross-sectional studies, prospective studies, case-control studies, nested casecontrol studies, nested case-cohort studies; (II) Studies that investigated the association of hypothyroidism, hyperthyroidism, or thyroid parameters (i.e., thyroid-stimulating hormone $[\mathrm{TSH}]$, free thyroxine $\left[\mathrm{FT}_{4}\right]$, free triiodothyronine $\left[\mathrm{FT}_{3}\right]$ ) with fibrosis of the liver, heart, or lung, in humans; (III) Studies reporting effect estimates (risk ratio, odds ratio or hazard ratio) with 95\% confidence intervals (Cls), or correlation coefficients ( $p$-values) used to correlate thyroid function with fibrosis, or mean differences (with standard deviations; p-values) in thyroid function between cases and controls, or mean differences (with standard deviations; p-values) in fibrotic scores between thyroid status categories, or prevalence differences (p-values). Case-reports, letters to the editor, proceedings, conference abstracts, reviews, systematic reviews, meta-analyses, and animal studies were excluded. The studies that focused exclusively on the role of thyroid function-altering 
medications on fibrotic diseases were also excluded. There were no restrictions on publication year or language.

Two independent reviewers ( $A B, S R)$ screened the titles and abstracts of the citations. The full texts of relevant articles were further obtained and independently evaluated. Any disagreement between the two reviewers regarding inclusion was resolved through consensus or with the help of a third independent reviewer. Full texts and reference lists of the selected articles were hand searched to identify additional studies. A predesigned data collection form was used to extract relevant information from the selected studies, including article source, sample size, demographics of study participants, methods of assessing thyroid function and fibrosis, study results and conclusions.

\section{Quality assessment}

The quality of the included studies was assessed separately by two reviewers (AB, SR) using the Newcastle-Ottawa Scale (NOS) for non-randomized studies in meta-analyses (Appendix 3a) $(38,39)$. The quality of cross-sectional studies was assessed by using an adapted NOS version (Appendix 3b). NOS evaluates the study quality based on 3 domains, namely selection of participants, comparability of study groups, and ascertainment of the exposure or outcome of interest. Each study could have a maximum of 9 stars. Based on the Agency for Healthcare Research and Quality (AHRQ) standards, the quality of the studies was categorized as poor, fair, and good; corresponding to high, moderate, and low risk of bias, respectively (Table 4$)(38,40)$.

\section{Statistical analyses}

For continuous outcomes, summary measures were presented as mean differences. To enhance the comparability among studies, we converted the units of measurements where appropriate. We used odds ratios (ORs) with their $95 \% \mathrm{Cls}$ as provided by the included articles, or calculated them manually using available information. Fixed-effects Mantel-Haenszel models were used to obtain pooled ORs with $95 \% \mathrm{Cls}$ for the association of hypothyroidism, overt and subclinical hypothyroidism with liver fibrosis (41). We constructed forest plots, and assessed heterogeneity by using the $I^{2}$ statistic, with $I^{2} \leq 25 \%$ considered as low, $25 \%<I^{2}<75 \%$ as moderate, and $I^{2} \geq 75 \%$ as high (42). The possibility of publication bias was assessed by using funnel plots and Egger regression symmetry tests (43). Statistical analyses were performed in Stata version 15.1 (StataCorp LLC, Texas, USA). 
Sensitivity analyses: The following sensitivity analyses were performed: (I) We used random-effects models in order to account for heterogeneity. (II) We excluded the studies that provided unadjusted estimates, thus limiting the meta-analysis to studies that accounted for relevant potential confounders. (III) To assess the impact of individual studies on the overall results, we calculated the pooled risk estimates after removing one by one the studies from the analyses. (IV) In order to account for a possible influence of thyroid medications on our results, the studies on hypothyroidism were stratified in studies including or excluding the thyroid medication users. (V) We performed subgroup analyses by stage of hypothyroidism (i.e., overt or subclinical hypothyroidism). (VI) The studies were stratified based on the source population (non-hospitalized versus hospitalized patients). (VII) We performed subgroup analyses by study design (i.e., crosssectional or longitudinal studies).

\section{RESULTS}

\section{Literature search}

The results of the search strategy are presented in Figure 1. After excluding duplicates, we identified 2196 relevant citations; and after further screening of abstracts, 63 potentially relevant articles were identified. Once the full texts of these articles were examined, 18 eligible unique studies were selected $(12,14,15,35,36,44-56)$.

\section{Thyroid function and fibrosis of the liver, lung and heart}

Table 1 summarizes the main characteristics of the 18 included studies reporting on the association of thyroid function with fibrosis of the liver, lung, and heart. The population sample size ranged from 36 to 7259 subjects (Table 1). The median mean age was 51 years (range, 36-69), and the median percentage of women was 53 (range, 17-100) (Table 1). Of the 18 included studies, 7 studies were performed in Asia (15, 44, 49, 50, 53-55), 6 in the United States (14, 35, 45, 46, 48, 51), 3 in Europe (12, 47, 52), 1 in Africa (56) and 1 in South America (36) (Table 1). Seventeen studies had a cross-sectional or case-control design, and 1 study had a prospective design (Table 1). Ten studies (14, 15, 35, 45, 47-50, $55,56)$ included hospitalized patients, 5 studies recruited participants from outpatient clinics $(36,44,46,52,53)$, and 3 studies included participants from the general population $(12,51,54)$ (Table 1). All studies controlled for confounders, except for 2 studies that reported unadjusted estimates $(35,36)$ (Table 1$)$. 
The studies reported on blood measurements of thyroid function (TSH, $\left.\mathrm{FT}_{4}, \mathrm{FT}_{3}\right)(12,35$, $47,49,50,52,54-56)$, overt hypothyroidism $(12,14,15,36,45,46,48,53,55)$, subclinical hypothyroidism $(12,44,50,51,55,56)$, and subclinical hyperthyroidism (12) (Table 2, Table 3). Of the 13 studies investigating hypothyroidism, 10 studies did not specify the cause of hypothyroidism and 3 studies defined hypothyroidism as Hashimoto's thyroiditis (Table 2). Several definitions of hypothyroidism were used. In 6 studies, the diagnosis of hypothyroidism was based on a self-reported disease history and use of thyroid hormone replacement therapy $(14,36,45,46,48,53)$ (Table 2). Seven studies diagnosed overt and subclinical hypothyroidism based on the serum TSH and $\mathrm{FT}_{4}$ measurements, after excluding the thyroid medication users $(12,15,44,50,51,55,56)$ (Table 2$)$. Nine studies excluded patients with past thyroid surgery (Table 2 ).

The outcomes were liver fibrosis (11 studies), myocardial fibrosis (4 studies), and fibrotic pulmonary diseases (3 studies) (Table 1). Of the studies assessing liver fibrosis, 7 studies used liver biopsy $(35,36,44-47,53), 3$ studies used fibrosis scores $(51,52,54)$, and 2 studies used liver elastography $(12,52)$ (Table 1 ). Myocardial fibrosis was assessed by cardiac magnetic resonance imaging, using measurements of myocardial longitudinal relaxation time T1-mapping ( 3 studies) $(15,50,55)$, or measurements of late gadolinium enhancement (1 study) (49) (Table 1). The fibrotic pulmonary diseases included IPF (idiopathic pulmonary fibrosis) (2 studies) $(14,56)$ and chronic hypersensitivity pneumonitis (CHPP) (1 study) (48) (Table 1). IPF and CHPP were diagnosed based on lung biopsy and computed tomography, according to the American Thoracic Society criteria (14, 48, 56) (Table 1).

The results of studies investigating the association of hypothyroidism with liver fibrosis were combined in a meta-analysis. The studies that were included in the meta-analysis used logistic regression to evaluate odds ratios. Due to the heterogeneity in methodology or differences in the assessment of fibrotic diseases, we could not perform quantitative meta-analyses for: (I) studies investigating the association of thyroid parameters with liver fibrosis; (II) studies on myocardial fibrosis; and (III) studies on pulmonary fibrosis. Liver fibrosis: Eleven studies investigated the association of thyroid status and/or thyroid parameters with liver fibrosis (Table 1). Of these, we identified 7 studies investigating the association of thyroid parameters $\left(\mathrm{TSH}, \mathrm{FT}_{4}, \mathrm{FT}_{3}\right)$ with liver fibrosis $(12,35,44,47,51,52$, 
54) (Table 3). In the general population, increasing TSH levels were associated with higher odds of liver fibrosis (OR, 1.49; $\mathrm{Cl}, 1.04-2.15$ per $1 \mathrm{log} \mathrm{TSH}$ ) (12) (Table 3). In euthyroid subjects, some studies reported no association of thyroid function with liver fibrosis (12, $35,44,54)$ and others reported an association of increasing TSH levels with liver fibrosis $(47,51)$ (Table 3). We also identified one study investigating subclinical hyperthyroidism and liver fibrosis, but without finding an association (OR, 0.80; $\mathrm{Cl}, 0.04-3.91)$ (12). Furthermore, we identified studies investigating the association of overt hypothyroidism ( 5 studies) $(12,36,45,46,53)$, and subclinical hypothyroidism (3 studies) $(12,44,51)$ with liver fibrosis (Table 2). Based on the results of the meta-analysis, the presence of hypothyroidism was associated with a higher risk of liver fibrosis compared to euthyroidism (pooled $\mathrm{OR}, 2.48 ; \mathrm{Cl}, 1.87-3.29$, heterogeneity $\mathrm{I}^{2}=0 \%$ ) (Figure 2a). In particular, clinical and subclinical hypothyroidism were associated with a higher risk of liver fibrosis compared to euthyroidism (pooled OR, 2.82; $\mathrm{Cl}, 1.95-4.07$, heterogeneity $I^{2}=31.4 \%$; pooled OR, 2.12; $\mathrm{Cl}, 1.45-3.12$, heterogeneity $I^{2}=0 \%$, respectively) $(12,36,44-46$, 51,53 ) (Figure $2 b$, Figure $2 c$ ). Sensitivity analyses using random-effects models provided similar estimates (pooled OR for overt hypothyroidism, 2.81; $\mathrm{Cl}, 1.74-4.53$; pooled OR for subclinical hypothyroidism, 2.12; $\mathrm{Cl}, 1.45-3.12)$ (Figure 2b, Figure 2c). After sensitivity analyses removing one by one the studies from the analyses, the results did not change substantially (pooled OR for overt hypothyroidism varying from 2.40 [1.52-3.78] to 3.19 [2.16-4.70]; pooled OR for subclinical hypothyroidism varying from 2.10 [1.28-3.43] to 2.16 [1.37-3.41]). After removing the study reporting unadjusted estimates (36), the association of overt hypothyroidism with liver fibrosis became stronger and the heterogeneity was eliminated (pooled OR, 3.19; $\mathrm{Cl}, 2.16-4.70$, heterogeneity $I^{2}=0 \%$ ). The studies that included patients with overt hypothyroidism being treated with thyroid hormones $(36,45,46,53)$ reported smaller ORs (pooled OR, 2.68; $\mathrm{Cl}, 1.84-3.92$ ) compared to the study that excluded thyroid medication users (OR, 6.64; $\mathrm{Cl}, 1.04-23.95)$ (12). The association of overt hypothyroidism with liver fibrosis was stronger in the studies recruiting participants from the outpatient clinic or general population (pooled $\mathrm{OR}, 3.06 ; \mathrm{Cl}, 1.56-6.0)(12,36,46,53)$ compared to the study that included hospitalized patients (OR, 2.30; $\mathrm{Cl}, 1.20-4.0)(45)$. The exclusion of the prospective study (12) from the analyses resulted in slightly smaller 
estimates for overt hypothyroidism (pooled $\mathrm{OR}, 2.68 ; \mathrm{Cl}, 1.84-3.92$ ) and subclinical hypothyroidism (pooled OR, 2.12; $\mathrm{Cl}, 1.17-4.01$ ).

Myocardial fibrosis: Four studies investigated the association of hypothyroidism and/or thyroid parameters with myocardial fibrosis $(15,49,50,55)$ (Table 1). Of these, 3 studies consistently showed that overt and subclinical hypothyroidism are associated with a higher degree of diffuse fibrosis than euthyroidism (Table 2$)(15,50,55)$. Two studies showed a positive correlation of TSH (correlation coefficients varying from 0.49 to 0.52 ) and a negative correlation of $\mathrm{FT}_{4}$ (correlation coefficients -0.48 for both studies) with myocardial fibrosis $(50,55)$, whereas another study did not find an association (49) (Table 3). Three studies showed a negative correlation of $\mathrm{FT}_{3}$ with myocardial fibrosis $(15,49,55)$ (Table 3$)$. Pulmonary fibrosis: Three case-control studies investigated the association of hypothyroidism with fibrotic diseases of the lung $(14,48,56)$ (Table 2). Overt hypothyroidism was associated with a 2.70 and 2.39 times higher odds of IPF and CHPP than euthyroidism, respectively, after adjusting for potential confounders as BMI, smoking, diabetes, and corticosteroid use $(14,48)$ (Table 2). Subclinical hypothyroidism was associated with a 8.58 times higher odds of IPF than euthyroidism, but the estimate was unadjusted for potential confounders (56) (Table 2).

\section{Quality assessment}

Study bias assessment scores are shown in Table 4. A total of 5 studies scored 5/9 stars, 6 studies scored 6/9 stars, 5 studies scored 7/9 stars, and 2 studies scored 8/9 stars (Table 4). Of the 18 included studies, 8 studies were rated as "poor quality", 6 studies were rated as "fair quality", and 4 studies were rated as "good quality" (Table 4).

\section{Assessment of publication bias}

The funnel plots for the association of hypothyroidism, overt hypothyroidism, and subclinical hypothyroidism with liver fibrosis are shown in Appendix 4. The Egger test did not indicate significant funnel plot asymmetry ( $p$-values, 0.9, 0.5, and 0.3, respectively) and thus provided no evidence of publication bias, although it should be noted that a maximum of 7 studies were included. 


\section{DISCUSSION}

This systematic review and meta-analysis summarize the current evidence regarding the role of thyroid function on fibrosis of the liver, heart and lung in humans. Overall, low thyroid function was associated with increased likelihood of fibrosis of the liver, heart, and lung. The association was consistent, irrespective of the diverse study populations, methodologies and fibrosis locations. The risk of bias of included studies was low to moderate to high.

Overt hypothyroidism was generally associated with higher likelihood of fibrosis compared to subclinical hypothyroidism, suggesting a dose-response relationship. The magnitudes of the associations differed across studies, which may be attributable to the differences in population characteristics, fibrosis locations, fibrosis assessment, and definitions of hypothyroidism used across studies. In general, studies that excluded thyroid medication users $(12,44)$ reported larger effect estimates compared to the studies that included hypothyroid patients treated with thyroid hormone replacement therapy $(14,45,46,48)$. In the latter group, it is possible that levothyroxine treatment may have reduced the risk of fibrosis, further resulting in an underestimation of the observed associations. The heterogeneity among studies examining the association of overt hypothyroidism with liver fibrosis was eliminated after removing the study by Mazo et al. (36). In this study, the lack of adjustment for confounders and the administration of levothyroxine may have led to an underestimation of the observed associations (36). Studies examining thyroid parameters generally concluded that increasing TSH levels were associated with higher likelihood of fibrosis $(12,47,50)$. Even in euthyroid subjects, low-normal thyroid function tended to be associated with increased likelihood of fibrosis, though sometimes not statistically significant $(12,44,47)$. This could be explained by insufficient sample sizes or by a lesser fibrotic response of low-normal thyroid function compared to low thyroid function.

The results of this systematic review of observational studies in humans are also supported by previous case reports and experimental studies (57-61). Case series and case reports in humans have indicated a co-occurrence of hypothyroidism and fibrotic diseases of the liver, heart, and lung (57-59). The diffuse myocardial injuries among patients with overt hypothyroidism were reversed by restoring euthyroidism with short-term levothyroxine treatment (60). In patients with severe hypothyroidism, the radiologic abnormalities 
suggestive of lung fibrosis were also reversed after receiving thyroid hormone replacement therapy (61). Furthermore, several animal studies suggested that fibrosis of the liver, heart, and lung, can be promoted by hypothyroidism and can be reversed by the administration of thyroid hormones $(17,18,20,24,27,62)$. Several mechanisms can explain the association of thyroid function with fibrotic diseases, including alterations in collagen gene expression, collagen deposition, activity of fibrogenic cytokines, and redox balance $(13,19-25,63)$. Fibrotic diseases of the liver, heart and lung share the common histological feature of extracellular matrix accumulation (64). Experimental hypothyroidism can lead to fibrosis via upregulation of the collagen type I gene expression $(13,19,20)$, whereas thyroid hormone administration reduces collagen type I gene expression $(22,24,25)$. Thyroid hormones also enhance the matrix metalloproteinase activity, further resulting in a collagen breakdown (65). The transforming growth factor beta (TGF $\beta$ ), a potent fibrogenic cytokine, is additionally involved in the development of hepatic, myocardial, and pulmonary fibrosis $(21,23,66$, 67). In hypothyroid patients, TGF $\beta$ triggers intracellular changes in SMAD proteins, which enter the nucleus, promoting collagen transcription and fibrosis (23). Thyroid hormones, on the other hand, antagonize the progression of fibrosis via inhibiting the TGFB/SMADdependent transcriptional activation (23). Thyroid hormone receptors may play a key role in mediating the aforementioned effects of thyroid hormones on hepatic, myocardial, and pulmonary fibrosis $(13,23,27)$. In experimental studies, thyromimetic compounds selective for thyroid hormone receptors have shown antifibrotic properties, whereas genetically ablated thyroid hormone receptors resulted in the development of fibrosis (13, 23, 27). Mitochondrial dysfunction is another mechanism that can explain the link between thyroid function and fibrosis $(68,69)$. Hypothyroidism has been associated with mitochondrial dysfunction and increased production of reactive oxygen species, which contribute to cell apoptosis and fibrosis $(68,69)$. This can be opposed by thyroid hormones, which improve mitochondrial function and attenuate oxidative stress (68-70). Furthermore, it may be speculated that autoimmune processes underlying hypothyroidism contribute to the development of fibrosis in the liver, heart and lung. Several studies in this systematic review reported that hypothyroid patients with Hashimoto`s thyroiditis had a higher likelihood of fibrotic diseases compared to euthyroid subjects $(15,50,55)$. 
However, none of the studies addressed whether the link between hypothyroidism and fibrotic diseases is independent of thyroid peroxidase antibodies or antithyroglobulin antibodies. Besides the shared pathways linking thyroid function to fibrosis of the liver, heart, and lung, underlying organ-specific mechanisms can play an additional role. For example, a hypothyroid state is associated with dyslipidemia, insulin resistance, and obesity, which in turn promote the development of liver steatosis that can eventually progress to cirrhosis (71-73). Moreover, hypothyroidism-associated lung fibrosis could be due to hypoxia, which improves when the hypothyroidism is treated (27).

One could also hypothesize that health-related problems underlying fibrotic diseases affect thyroid parameters. Severe illnesses (e.g., sepsis, hypoxia, chronic illnesses) may result in "non-thyroidal illness", a condition which is characterized by normal or lownormal serum TSH, low serum FT3 and low serum FT4 levels (74). Although the exact mechanisms underlying non-thyroidal illness remain unclear, poor health states can stimulate a dysregulation of hypothalamus-pituitary-thyroid axis and alterations in the expression of thyroid hormone receptors, transporters or deiodinases, which can eventually lead to changes in thyroid hormone levels. The results of this systematic review, however, are not likely explained by non-thyroidal illness, because the included studies were not performed in critically ill populations. The studies that were performed in hospitalized populations usually excluded the patients with chronic and decompensated conditions. The other studies were conducted in relatively healthy participants from the general population or outpatient clinics.

To the best of our knowledge, this is the first systematic review, which combines the literature regarding the role of thyroid function on fibrosis of the liver, heart and lung, in humans. In accordance with the NOS scale, we used strict criteria for the quality assessment of the risk of bias. Most of the included studies adjusted for potential confounders, including age and sex. Another strength is the consistency of the results in the setting of diverse study populations. The wide range of ages (mean age ranging from 36 to 69) and ethnicities of participants may increase the generalizability of our conclusions. Furthermore, we were able to perform summary statistics, and combine the available evidence on hypothyroidism and liver fibrosis in a meta-analysis. Sensitivity analyses provided consistent estimates. No evidence of publication bias was observed. 
Several limitations of this systematic review warrant consideration. Most of the included studies were characterized by a cross-sectional design; therefore, we cannot exclude the possibility of reverse causation or bidirectional associations. The results of cross-sectional studies in this systematic review, however, were in line with the results of the prospective study (12) suggesting a temporal association between low thyroid function and fibrosis risk. Additional evidence from experimental studies supports more strongly an effect of hypothyroidism on fibrotic diseases rather than vice-versa $(17,18,20,24,27)$. Another limitation of this systematic review is that the included studies used several definitions of thyroid dysfunction and different measures of fibrotic outcomes. Nevertheless, results were overall consistent. The studies defining thyroid status based on thyroid function measurements did not have data available with regard to variations in thyroid function over time. Furthermore, the limited number of identified studies illustrates the scarcity of evidence on this topic, especially for myocardial and pulmonary fibrosis.

Future population-based studies examining the association of thyroid dysfunction (i.e., hypothyroidism and hyperthyroidism) with the risk of fibrotic diseases should preferably be characterized by a prospective design and a long-term follow-up period. Adequately powered studies are also needed to clarify whether the risk of fibrosis is affected by the fluctuations within the reference range of thyroid function. Of importance, future randomized clinical trials are warranted to simultaneously examine the potential beneficial effects of thyroid hormone supplementation on fibrosis of the liver, heart and lung. These investigations could eventually promote the development of new therapies against fibrotic diseases. In addition, thyroid disease may also play a role in the development of other fibrotic processes, including idiopathic retroperitoneal fibrosis, primary biliary cirrhosis, and skin fibrosis; but the amount of current evidence is very limited and further research is needed $(23,75,76)$. Given the systemic effects of thyroid hormones, future studies may also consider investigating the association of thyroid function with the risk of concomitant fibrotic processes in multiple organs. Finally, future observational and experimental studies need to provide additional insights on the shared and organ-specific mechanisms linking thyroid function to fibrosis of the liver, heart and lung, using mediation analyses and interventional approaches. In particular, it remains uncertain whether the link between thyroid function and fibrotic diseases is independent of thyroid autoimmunity, 
hypoxia and chronic illnesses. Given the complexity of the mechanisms underlying fibrosis, future studies may need to unravel the interplay of thyroid hormones with inflammatory, hormonal, metabolic, immune, environmental, genetic, and other putative risk factors of fibrotic diseases.

\section{Conclusions}

Our findings suggest that low thyroid function is associated with an increased likelihood of chronic fibrotic diseases of the liver, heart, and lung, in humans. Results were consistent in the setting of diverse study populations. Given the limited amount of prospective evidence on this topic, our study highlights the need for future prospective studies and randomized clinical trials investigating the potential efficacy of thyroid hormone and its analogues on the development of fibrosis. This could eventually lead to the development of novel strategies for the prevention and treatment of the fibrotic diseases.

\section{Acknowledgements}

We would like to thank the librarians from the Walton Library of Newcastle University and the librarians from the Medical Library at the University of Bern, for their assistance with the online literature search. Dr. Arjola Bano was supported by an exchange fellowship from the European Thyroid Association. Prof. R.P. Peeters is supported by the Netherlands Organization for Health Research and Development Zon-MWTOP grant 91212044 and an Erasmus Medical Center Medical Research Advisory Committee grant. Prof. R. P. Peeters has received lecture fees from IBSA and Goodlife Fertility. The funding sources had no role in the selection, critical appraisal, or synthesis of evidence.

\section{Author Disclosure Statement}

No competing financial interests exist.

\section{Corresponding Author}

Arjola Bano, MD, PhD

Postdoctoral researcher. University of Bern.

Office 480. Mittelstrasse 43, 3012. Bern, Switzerland

Tel +41316315567

arjola.bano@ispm.unibe.ch

ORCID: 0000-0003-0956-7145 


\section{REFERENCES}

1. Wynn TA 2007 Common and unique mechanisms regulate fibrosis in various fibroproliferative diseases. The Journal of clinical investigation 117:524-529.

2. Agarwal I, Glazer NL, Barasch E, Biggs ML, Djousse L, Fitzpatrick AL, Gottdiener JS, IX JH, Kizer JR, Rimm EB, Siscovick DS, Tracy RP, Zieman SJ, Mukamal KJ 2014 Fibrosisrelated biomarkers and risk of total and cause-specific mortality: the cardiovascular health study. American journal of epidemiology 179:1331-1339.

3. Mozaffarian D, Benjamin EJ, Go AS, Arnett DK, Blaha MJ, Cushman M, de Ferranti S, Despres JP, Fullerton HJ, Howard VJ, Huffman MD, Judd SE, Kissela BM, Lackland DT, Lichtman JH, Lisabeth LD, Liu S, Mackey RH, Matchar DB, McGuire DK, Mohler ER, 3rd, Moy CS, Muntner P, Mussolino ME, Nasir K, Neumar RW, Nichol G, Palaniappan L, Pandey DK, Reeves MJ, Rodriguez CJ, Sorlie PD, Stein J, Towfighi A, Turan TN, Virani SS, Willey JZ, Woo D, Yeh RW, Turner MB 2015 Heart disease and stroke statistics--2015 update: a report from the American Heart Association. Circulation 131:e29-322.

4. Martinez FJ, Safrin S, Weycker D, Starko KM, Bradford WZ, King TE, Jr., Flaherty KR, Schwartz DA, Noble PW, Raghu G, Brown KK 2005 The clinical course of patients with idiopathic pulmonary fibrosis. Annals of internal medicine 142:963-967.

5. Wynn TA 2008 Cellular and molecular mechanisms of fibrosis. The Journal of pathology 214:199-210.

6. Rinella ME 2015 Nonalcoholic fatty liver disease: a systematic review. Jama 313:2263-2273.

7. Conrad CH, Brooks WW, Hayes JA, Sen S, Robinson KG, Bing OH 1995 Myocardial fibrosis and stiffness with hypertrophy and heart failure in the spontaneously hypertensive rat. Circulation 91:161-170.

8. Ryu JH, Moua T, Daniels CE, Hartman TE, Yi ES, Utz JP, Limper AH 2014 Idiopathic pulmonary fibrosis: evolving concepts. Mayo Clinic proceedings 89:1130-1142.

9. Wynn TA, Ramalingam TR 2012 Mechanisms of fibrosis: therapeutic translation for fibrotic disease. Nature medicine 18:1028-1040. 
10. Ghosh AK, Quaggin SE, Vaughan DE 2013 Molecular basis of organ fibrosis: potential therapeutic approaches. Experimental biology and medicine (Maywood, NJ) 238:461-481.

11. Friedman SL, Sheppard D, Duffield JS, Violette S 2013 Therapy for fibrotic diseases: nearing the starting line. Science translational medicine 5:167sr161.

12. Bano A, Chaker L, Plompen EP, Hofman A, Dehghan A, Franco OH, Janssen HL, Darwish Murad S, Peeters RP 2016 Thyroid Function and the Risk of Nonalcoholic Fatty Liver Disease: The Rotterdam Study. The Journal of clinical endocrinology and metabolism 101:3204-3211.

13. Chen WJ, Lin $\mathrm{KH}$, Lee YS 2000 Molecular characterization of myocardial fibrosis during hypothyroidism: evidence for negative regulation of the pro-alpha1(I) collagen gene expression by thyroid hormone receptor. Molecular and cellular endocrinology 162:45-55.

14. Oldham JM, Kumar D, Lee C, Patel SB, Takahashi-Manns S, Demchuk C, Strek ME, Noth I 2015 Thyroid Disease Is Prevalent and Predicts Survival in Patients With Idiopathic Pulmonary Fibrosis. Chest 148:692-700.

15. Gao X, Liu M, Qu A, Chen Z, Jia Y, Yang N, Feng X, Liu J, Xu Y, Yang X, Wang G 2016 Native Magnetic Resonance T1-Mapping Identifies Diffuse Myocardial Injury in Hypothyroidism. PloS one 11:e0151266.

16. Hierholzer K, Finke R 1997 Myxedema. Kidney international Supplement 59:S82-89.

17. Rodriguez-Castelan J, Corona-Perez A, Nicolas-Toledo L, Martinez-Gomez M, Castelan F, Cuevas-Romero E 2017 Hypothyroidism Induces a Moderate Steatohepatitis Accompanied by Liver Regeneration, Mast Cells Infiltration, and Changes in the Expression of the Farnesoid X Receptor. Experimental and clinical endocrinology and diabetes 125:183-190.

18. Dzhulay GS, Shchelochenkov SV, Petrova MB, Bibikova AA 2016 Experimental posttiroidectomic fatty liver disease in rats Experimental and clinical gastroenterology:35-39.

19. Klein LE, Sigel AV, Douglas JA, Eghbali-Webb M 1996 Upregulation of collagen type I gene expression in the ventricular myocardium of thyroidectomized male and female rats. Journal of molecular and cellular cardiology 28:33-42. 
20. Drobnik J, Ciosek J, Slotwinska D, Stempniak B, Zukowska D, Marczynski A, Tosik D, Bartel H, Dabrowski R, Szczepanowska A 2009 Experimental hypothyroidism increases content of collagen and glycosaminoglycans in the heart. Journal of physiology and pharmacology : an official journal of the Polish Physiological Society 60:57-62.

21. Hajje G, Saliba Y, Itani T, Moubarak M, Aftimos G, Fares N 2014 Hypothyroidism and its rapid correction alter cardiac remodeling. PloS one 9:e109753.

22. Lissoos TW, Beno DW, Davis BH 1993 Posttranslational inhibition of Ito cell type I collagen production by triiodothyronine. The American journal of physiology 264:G1090-1095.

23. Alonso-Merino E, Martin Orozco R, Ruiz-Llorente L, Martinez-Iglesias OA, VelascoMartin JP, Montero-Pedrazuela A, Fanjul-Rodriguez L, Contreras-Jurado C, Regadera J, Aranda A 2016 Thyroid hormones inhibit TGF-beta signaling and attenuate fibrotic responses. Proceedings of the National Academy of Sciences of the United States of America 113:E3451-3460.

24. Yao J, Eghbali M 1992 Decreased collagen mRNA and regression of cardiac fibrosis in the ventricular myocardium of the tight skin mouse following thyroid hormone treatment. Cardiovascular research 26:603-607.

25. Lee HW, Klein LE, Raser J, Eghbali-Webb M 1998 An activator protein-1 (AP-1) response element on pro alpha1(I) collagen gene is necessary for thyroid hormoneinduced inhibition of promoter activity in cardiac fibroblasts. Journal of molecular and cellular cardiology 30:2495-2506.

26. Nicolini G, Forini F, Kusmic C, Pitto L, Mariani L, lervasi G 2015 Early and short-term triiodothyronine supplementation prevents adverse post-ischemic cardiac remodeling: role of transforming growth factor-beta1 and anti-fibrotic miRNA signaling. Molecular medicine (Cambridge, Mass).

27. Yu G, Tzouvelekis A, Wang R, Herazo-Maya JD, Ibarra GH, Srivastava A, de Castro JPW, Deluliis G, Ahangari F, Woolard T, Aurelien N, Arrojo EDR, Gan Y, Graham M, Liu X, Homer RJ, Scanlan TS, Mannam P, Lee PJ, Herzog EL, Bianco AC, Kaminski N 2018 Thyroid hormone inhibits lung fibrosis in mice by improving epithelial mitochondrial function. Nature medicine 24:39-49. 
28. Oren R, Brill S, Dotan I, Halpern Z 1998 Liver function in cirrhotic patients in the euthyroid versus the hypothyroid state. Journal of clinical gastroenterology 27:339341.

29. Bruck R, Weiss S, Traister A, Zvibel I, Aeed H, Halpern Z, Oren R 2007 Induced hypothyroidism accelerates the regression of liver fibrosis in rats. Journal of gastroenterology and hepatology 22:2189-2194.

30. Zvibel I, Atias D, Phillips A, Halpern Z, Oren R 2010 Thyroid hormones induce activation of rat hepatic stellate cells through increased expression of p75 neurotrophin receptor and direct activation of Rho. Laboratory investigation 90:674-684.

31. Gomaa AM, Abd El-Aziz EA 2016 Omega-3 fatty acids decreases oxidative stress, tumor necrosis factor-alpha, and interleukin-1 beta in hyperthyroidism-induced hepatic dysfunction rat model. Pathophysiology 23:295-301.

32. Weltman NY, Wang D, Redetzke RA, Gerdes AM 2012 Longstanding hyperthyroidism is associated with normal or enhanced intrinsic cardiomyocyte function despite decline in global cardiac function. PloS one 7:e46655.

33. Schuman ML, Peres Diaz LS, Landa MS, Toblli JE, Cao G, Alvarez AL, Finkielman S, Pirola CJ, Garcia SI 2014 Thyrotropin-releasing hormone overexpression induces structural changes of the left ventricle in the normal rat heart. American journal of physiology Heart and circulatory physiology 307:H1667-1674.

34. Levick S, Fenning A, Brown L 2005 Increased calcium influx mediates increased cardiac stiffness in hyperthyroid rats. Cell biochemistry and biophysics 43:53-60.

35. Bril F, Kadiyala S, Portillo Sanchez P, Sunny NE, Biernacki D, Maximos $M$, Kalavalapalli S, Lomonaco R, Suman A, Cusi K 2016 Plasma thyroid hormone concentration is associated with hepatic triglyceride content in patients with type 2 diabetes. Journal of investigative medicine 64:63-68.

36. Mazo DF, Lima VM, Stefano JT, Rabelo F, Faintuch J, Oliveira CP 2011 Gluco-lipidic indices in treated hypothyroidism associated with nonalcoholic fatty liver disease. Arquivos de gastroenterologia 48:186-189. 
37. Moher D, Liberati A, Tetzlaff J, Altman DG 2009 Preferred reporting items for systematic reviews and meta-analyses: the PRISMA statement. PLoS medicine 6:e1000097.

38. Wells GA SB, O'Connell D, Peterson J, Welch V, Losos M, Tugwell P. 2014 The Newcastle-Ottawa Scale (NOS) for assessing the quality of nonrandomised studies in meta-analyses http://wwwohrica/programs/clinical_epidemiology/oxfordasp.

39. Stang A 2010 Critical evaluation of the Newcastle-Ottawa scale for the assessment of the quality of nonrandomized studies in meta-analyses. European journal of epidemiology 25:603-605.

40. Borge TC, Aase H, Brantsaeter AL, Biele G 2017 The importance of maternal diet quality during pregnancy on cognitive and behavioural outcomes in children: a systematic review and meta-analysis. BMJ open 7:e016777.

41. DerSimonian R, Laird N 1986 Meta-analysis in clinical trials. Controlled clinical trials 7:177-188

42. Higgins JP, Thompson SG, Deeks JJ, Altman DG 2003 Measuring inconsistency in meta-analyses. BMJ (Clinical research ed) 327:557-560.

43. Egger M, Davey Smith G, Schneider M, Minder C 1997 Bias in meta-analysis detected by a simple, graphical test. BMJ 315:629-634.

44. Kim D, Kim W, Joo SK, Bae JM, Kim JH, Ahmed A 2018 Subclinical Hypothyroidism and Low-Normal Thyroid Function Are Associated With Nonalcoholic Steatohepatitis and Fibrosis. Clinical gastroenterology and hepatology 16:123131.e121.

45. Liangpunsakul S, Chalasani N 2003 Is hypothyroidism a risk factor for non-alcoholic steatohepatitis? Journal of clinical gastroenterology 37:340-343.

46. Pagadala MR, Zein CO, Dasarathy S, Yerian LM, Lopez R, McCullough AJ 2012 Prevalence of hypothyroidism in nonalcoholic fatty liver disease. Digestive diseases and sciences 57:528-534.

47. Carulli L, Ballestri S, Lonardo A, Lami F, Violi E, Losi L, Bonilauri L, Verrone AM, Odoardi MR, Scaglioni F, Bertolotti M, Loria P 2013 Is nonalcoholic steatohepatitis associated with a high-though-normal thyroid stimulating hormone level and lower cholesterol levels? Internal and emergency medicine 8:297-305. 
48. Adegunsoye A, Oldham JM, Husain AN, Chen L, Hsu S, Montner S, Chung JH, Vij R, Noth I, Strek ME 2017 Autoimmune Hypothyroidism As a Predictor of Mortality in Chronic Hypersensitivity Pneumonitis. Frontiers in medicine 4:170.

49. Wang W, Guan H, Fang W, Zhang K, Gerdes AM, lervasi G, Tang YD 2016 Free Triiodothyronine Level Correlates with Myocardial Injury and Prognosis in Idiopathic Dilated Cardiomyopathy: Evidence from Cardiac MRI and SPECT/PET Imaging. Scientific reports 6:39811.

50. Yao Z, Gao X, Liu M, Chen Z, Yang N, Jia YM, Feng XM, Xu Y, Yang XC, Wang G 2018 Diffuse Myocardial Injuries are Present in Subclinical Hypothyroidism: A Clinical Study Using Myocardial T1-mapping Quantification. Scientific reports 8:4999.

51. Kim D, Yoo ER, Li AA, Fernandes CT, Tighe SP, Cholankeril G, Hameed B, Ahmed A 2019 Low-Normal Thyroid Function Is Associated With Advanced Fibrosis Among Adults in the United States. Clinical gastroenterology and hepatology 17:2379-2381.

52. Manka P, Bechmann L, Best J, Sydor S, Claridge LC, Coombes JD, Canbay A, Moeller L, Gerken G, Wedemeyer H, Syn WK 2019 Low Free Triiodothyronine Is Associated with Advanced Fibrosis in Patients at High Risk for Nonalcoholic Steatohepatitis. Digestive diseases and sciences 64:2351-2358.

53. Parikh P, Phadke A, Sawant P 2015 Prevalence of hypothyroidism in nonalcoholic fatty liver disease in patients attending a tertiary hospital in western India. Indian journal of gastroenterology 34:169-173.

54. Liu Y, Wang W, Yu X, Qi X 2018 Thyroid Function and Risk of Non-Alcoholic Fatty Liver Disease in Euthyroid Subjects. Annals of hepatology 17:779-788.

55. Liu M, Liu W, Zhang P, An J, Wang G 2019 Left ventricular myocardial T1 mapping and strain analysis evaluate cardiac abnormality in hypothyroidism. The international journal of cardiovascular imaging 35:507-515.

56. Aboelnaga HH, Elsherbeny AA, Abdelhady EA 2019 Idiopathic pulmonary fibrosis and subclinical hypothyroidism: An underestimated comorbidity. Egyptian Journal of Chest Diseases and Tuberculosis 68:50-56.

57. Awano N, Izumo T, Fukuda K, Tone M, Yamada D, Takemura T, Ikushima S, Kumasaka T 2018 Is hypothyroidism in idiopathic pleuroparenchymal fibroelastosis a novel lung-thyroid syndrome? Respiratory investigation 56:48-56. 
58. Rajaram P, Little B, Norvell JP, McLemore M, Veeraraghavan S 2016 A 49-Year-Old Man With Cirrhosis and Pulmonary Fibrosis. Chest 149:e57-e60.

59. Okabe M, Kubara K, Kawaguchi H, Kawano T, Nakashima Y, Fukuda K, Hiroki T, Arakawa K, Kikuchi M 1990 A case of myxedema with diffuse myocardial fibrosis proven by endomyocardial biopsy. Kokyu to junkan Respiration \& circulation 38:1159-1163.

60. Gao X, Chen Z, Liu M, Jia YM, Yang N, Yao Z, Feng XM, Xu Y, Wang G 2017 Effects of short-term levothyroxine therapy on myocardial injuries in patients with severe overt hypothyroidism: Evidence from a cardiac MRI Study. Journal of magnetic resonance imaging : JMRI 46:897-904.

61. George JT, Thow JC, Rodger KA, Mannion R, Jayagopal V 2009 Reversibility of fibrotic appearance of lungs with thyroxine replacement therapy in patients with severe hypothyroidism. Endocrine practice 15:720-724.

62. Perra A, Simbula G, Simbula M, Pibiri M, Kowalik MA, Sulas P, Cocco MT, LeddaColumbano GM, Columbano A 2008 Thyroid hormone (T3) and TRbeta agonist GC-1 inhibit/reverse nonalcoholic fatty liver in rats. FASEB journal 22:2981-2989.

63. Eghbali M 1993 Molecular and cellular mechanisms of induction and regression of cardiac fibrosis in various models of myocardial hypertrophy. Cardiovascular pathology 2:199-205.

64. Nanthakumar CB, Hatley RJ, Lemma S, Gauldie J, Marshall RP, Macdonald SJ 2015 Dissecting fibrosis: therapeutic insights from the small-molecule toolbox. Nature reviews Drug discovery 14:693-720.

65. Ghose Roy S, Mishra S, Ghosh G, Bandyopadhyay A 2007 Thyroid hormone induces myocardial matrix degradation by activating matrix metalloproteinase-1. Matrix biology 26:269-279.

66. Yue Y, Meng K, Pu Y, Zhang X 2017 Transforming growth factor beta (TGF-beta) mediates cardiac fibrosis and induces diabetic cardiomyopathy. Diabetes research and clinical practice 133:124-130.

67. Khalil H, Kanisicak O, Prasad V, Correll RN, Fu X, Schips T, Vagnozzi RJ, Liu R, Huynh T, Lee SJ, Karch J, Molkentin JD 2017 Fibroblast-specific TGF-beta-Smad2/3 signaling underlies cardiac fibrosis. The Journal of clinical investigation 127:3770-3783. 
68. Baskol G, Atmaca H, Tanriverdi F, Baskol M, Kocer D, Bayram F 2007 Oxidative stress and enzymatic antioxidant status in patients with hypothyroidism before and after treatment. Experimental and clinical endocrinology and diabetes 115:522-526.

69. Kennett EC, Chuang CY, Degendorfer G, Whitelock JM, Davies MJ 2011 Mechanisms and consequences of oxidative damage to extracellular matrix. Biochemical Society transactions 39:1279-1287.

70. Madathil A, Hollingsworth KG, Blamire AM, Razvi S, Newton JL, Taylor R, Weaver JU 2015 Levothyroxine improves abnormal cardiac bioenergetics in subclinical hypothyroidism: a cardiac magnetic resonance spectroscopic study. The Journal of clinical endocrinology and metabolism 100:E607-610.

71. Loria P, Carulli L, Bertolotti M, Lonardo A 2009 Endocrine and liver interaction: the role of endocrine pathways in NASH. Nature reviews Gastroenterology \& hepatology 6:236-247.

72. Maratou E, Hadjidakis DJ, Kollias A, Tsegka K, Peppa M, Alevizaki M, Mitrou P, Lambadiari V, Boutati E, Nikzas D, Tountas N, Economopoulos T, Raptis SA, Dimitriadis G 2009 Studies of insulin resistance in patients with clinical and subclinical hypothyroidism. European journal of endocrinology 160:785-790.

73. Angulo P, Keach JC, Batts KP, Lindor KD 1999 Independent predictors of liver fibrosis in patients with nonalcoholic steatohepatitis. Hepatology (Baltimore, Md) 30:13561362.

74. Fliers E, Bianco AC, Langouche L, Boelen A 2015 Thyroid function in critically ill patients. The lancet Diabetes \& endocrinology 3:816-825.

75. Elta GH, Sepersky RA, Goldberg MJ, Connors CM, Miller KB, Kaplan MM 1983 Increased incidence of hypothyroidism in primary biliary cirrhosis. Digestive diseases and sciences 28:971-975.

76. Ceresini G, Urban ML, Corradi D, Lauretani F, Marina M, Usberti E, Palmisano A, Buzio C, Vaglio A 2015 Association between idiopathic retroperitoneal fibrosis and autoimmune thyroiditis: a case-control study. Autoimmunity reviews 14:16-22. 
Table 1. Description of included studies on the association of thyroid function with fibrosis of the liver, heart and lung*

\begin{tabular}{|c|c|c|c|c|c|c|c|c|}
\hline $\begin{array}{l}\text { First } \\
\text { author, } \\
\text { year }\end{array}$ & Country & $\mathbf{N}$ & $\begin{array}{l}\text { Age } \\
\text { (me } \\
\text { an) }\end{array}$ & $\begin{array}{l}\% \\
\text { Wo } \\
\text { men }\end{array}$ & $\begin{array}{l}\text { Study } \\
\text { design }\end{array}$ & $\begin{array}{l}\text { Populati } \\
\text { on }\end{array}$ & $\begin{array}{l}\text { Adjustment/ } \\
\text { Matching (if } \\
\text { applicable) }\end{array}$ & $\begin{array}{l}\text { Outcome } \\
\text { (Assessm } \\
\text { ent) }\end{array}$ \\
\hline (Referenc & & & & & & & & \\
\hline e) & & & & & & & & \\
\hline
\end{tabular}

\section{Thyroid function and liver fibrosis}

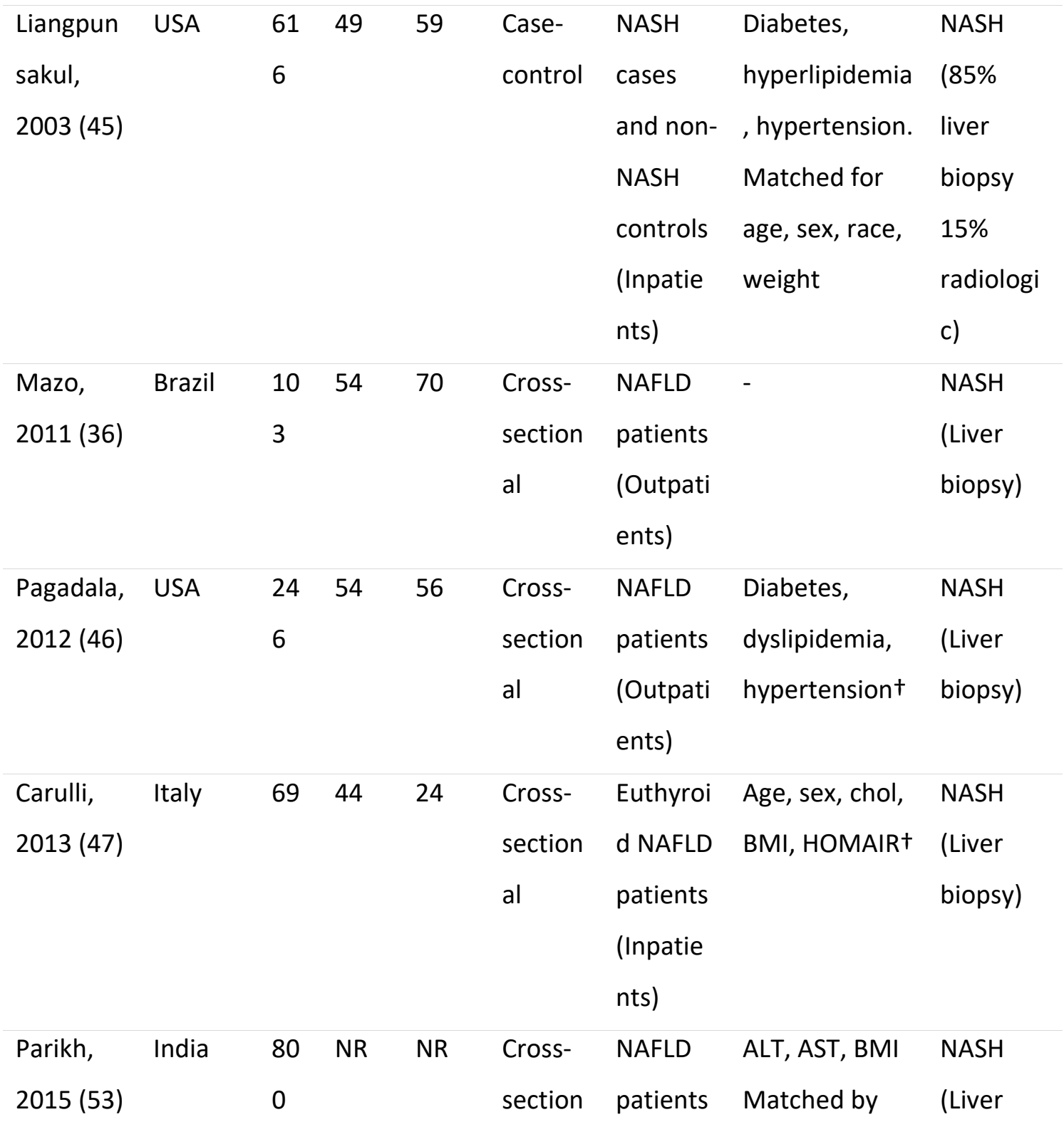




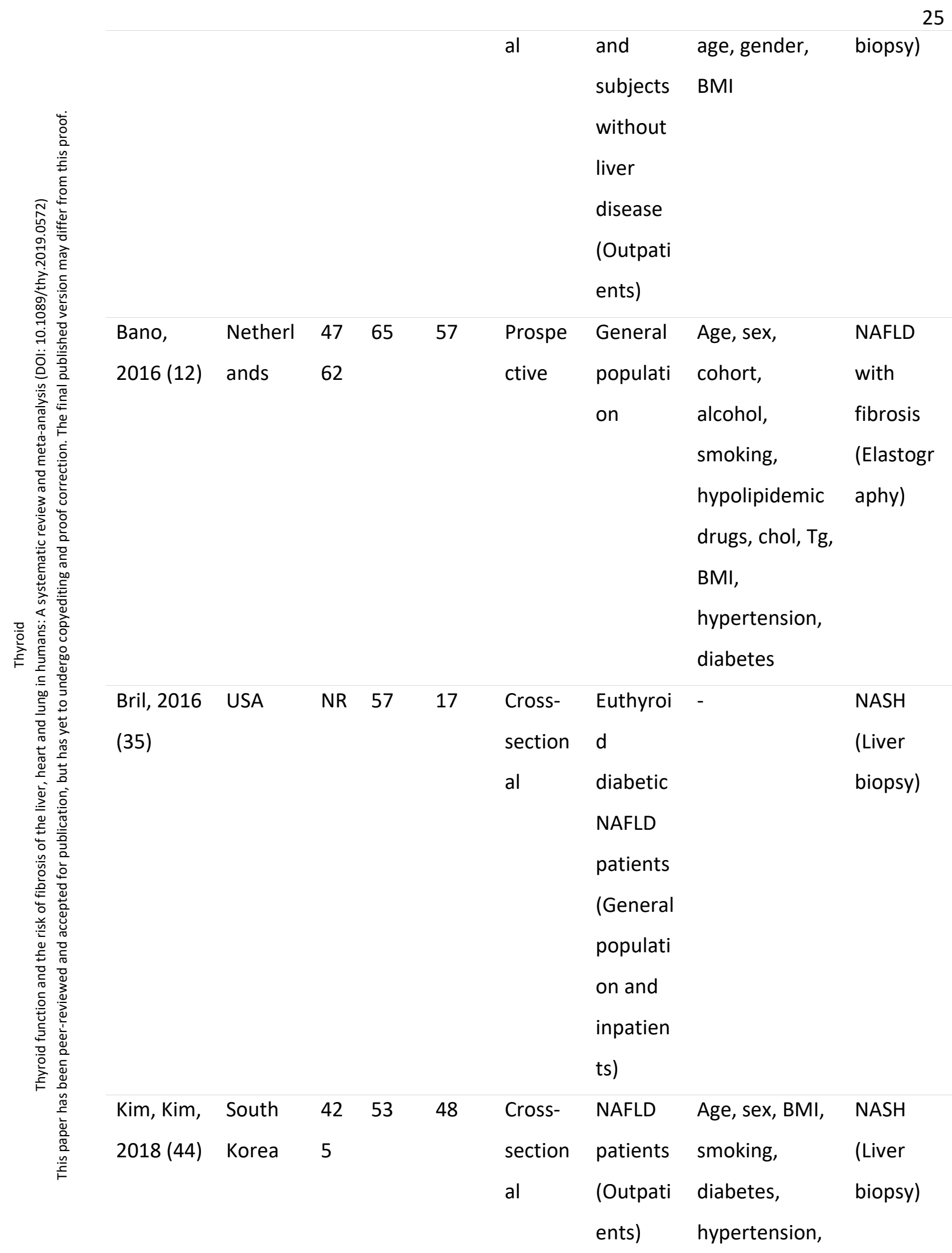




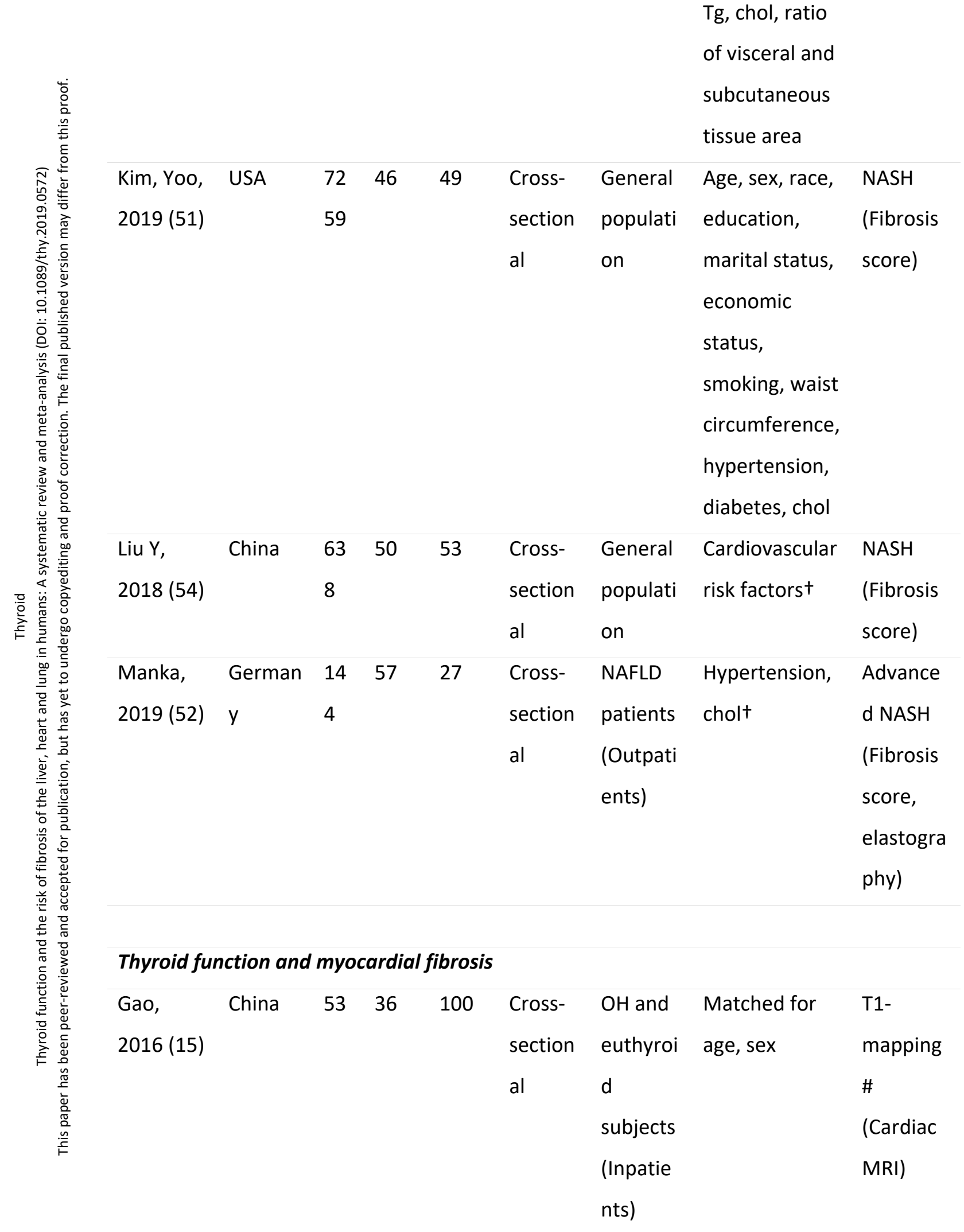




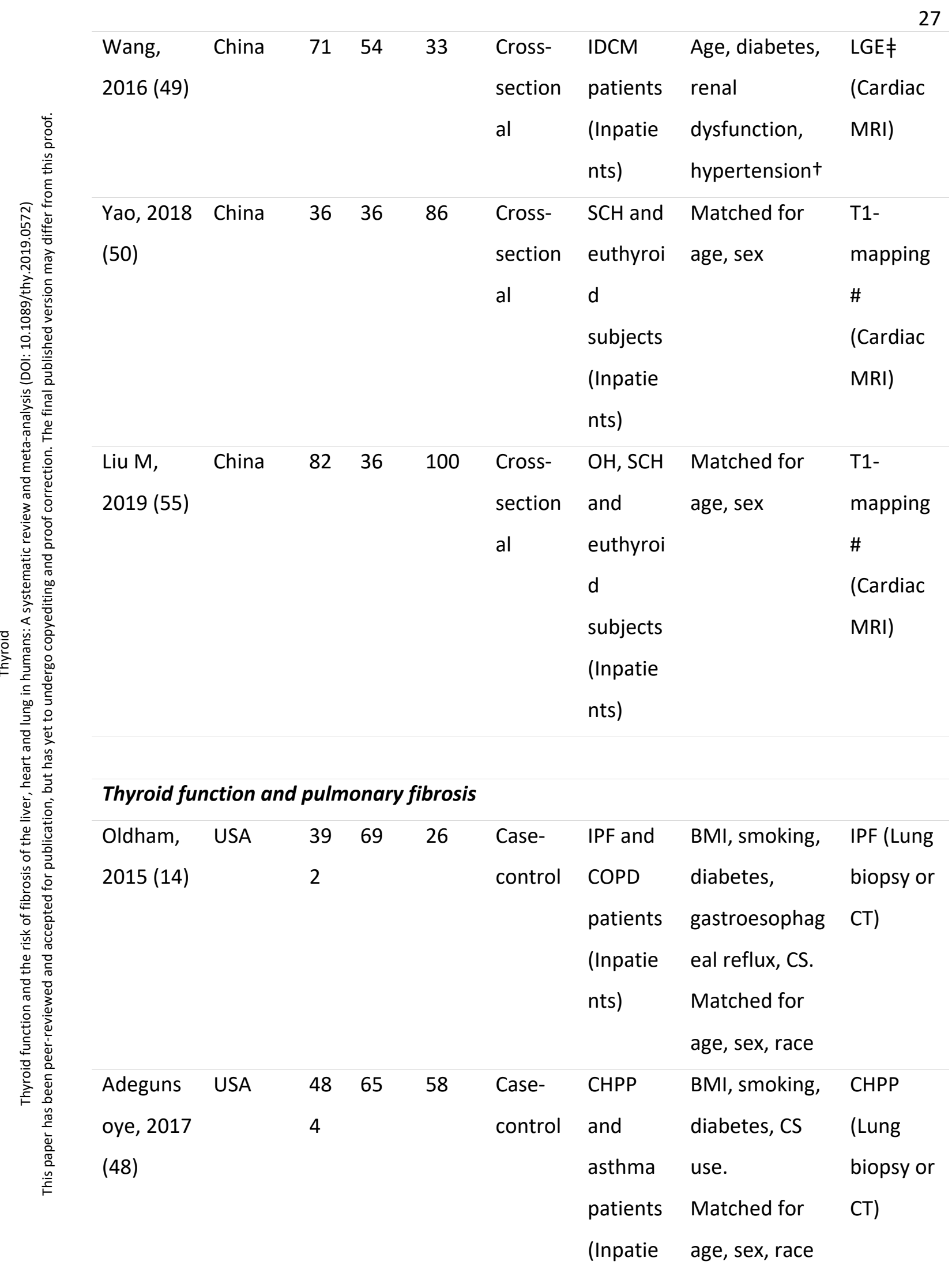


nts)

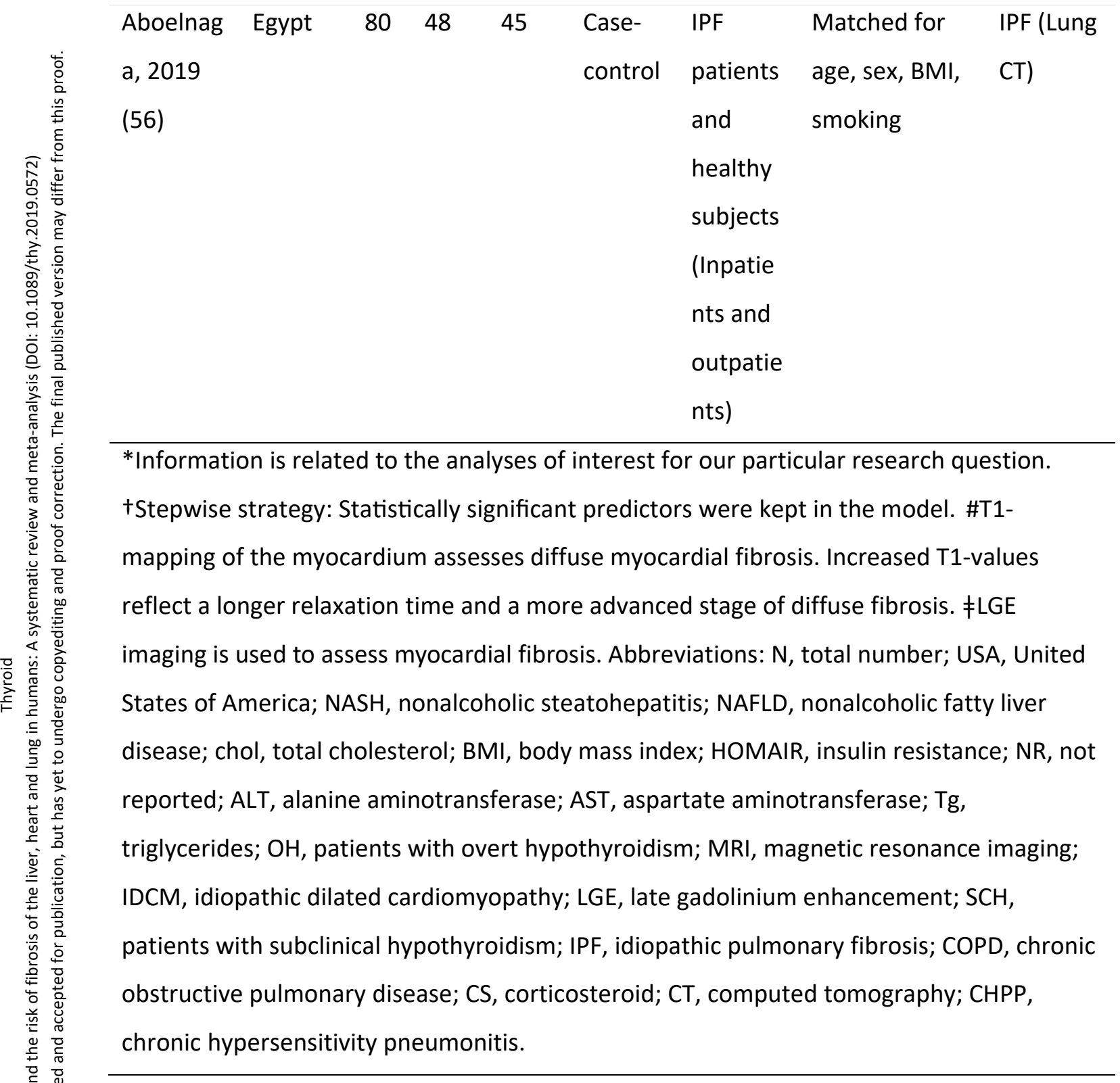




\begin{tabular}{|c|c|c|c|c|c|c|}
\hline \multirow{8}{*}{ 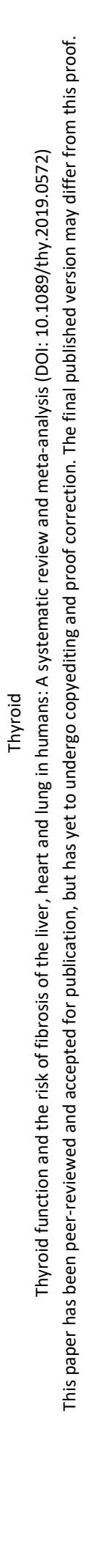 } & \multicolumn{6}{|c|}{$\begin{array}{l}\text { Table 2. Description of studies repol } \\
\text { fibrosis of the liver, heart and lung }\end{array}$} \\
\hline & $\begin{array}{l}\text { First author, } \\
\text { year } \\
\text { (Reference) }\end{array}$ & $\begin{array}{l}\text { Hypothyroidis } \\
\text { m }\end{array}$ & $\begin{array}{l}\text { Cause of } \\
\text { hypothyroidis } \\
\text { m }\end{array}$ & $\begin{array}{l}\text { Diagnosis of } \\
\text { hypothyroidis } \\
\text { m }\end{array}$ & $\begin{array}{l}\text { Outcome } \\
\text { (Referenc } \\
\text { e) }\end{array}$ & $\begin{array}{l}\text { Effect } \\
\text { estimate }\end{array}$ \\
\hline & Liver fibrosis & & & & & $O R(C I)$ \\
\hline & $\begin{array}{l}\text { Liangpunsaku } \\
\text { I, } 2003 \text { (45) }\end{array}$ & Overt & NS & $\begin{array}{l}\text { Previous } \\
\text { diagnosis of } \\
\text { hypothyroidis } \\
m \text {, and use of } \\
\text { THR }\end{array}$ & $\begin{array}{l}\text { NASH } \\
\text { (Non- } \\
\text { NASH) }\end{array}$ & $\begin{array}{l}2.30 \\
(1.20- \\
4.0)\end{array}$ \\
\hline & $\begin{array}{l}\text { Mazo, } 2011 \\
(36)\end{array}$ & Overt & NS & $\begin{array}{l}\text { Previous } \\
\text { diagnosis of } \\
\text { hypothyroidis } \\
m \text {, and use of } \\
\text { THR }\end{array}$ & $\begin{array}{l}\text { NASH } \\
\text { (Steatosis) }\end{array}$ & $\begin{array}{l}1.04 \\
(0.34- \\
3.15)\end{array}$ \\
\hline & $\begin{array}{l}\text { Pagadala, } \\
2012(46)\end{array}$ & Overt & NS & $\begin{array}{l}\text { Previous } \\
\text { diagnosis of } \\
\text { hypothyroidis } \\
m \text {, and use of } \\
\text { THR }\end{array}$ & $\begin{array}{l}\text { NASH } \\
\text { (Steatosis) }\end{array}$ & $\begin{array}{l}3.80 \\
(2.0- \\
6.90)\end{array}$ \\
\hline & $\begin{array}{l}\text { Parikh, } 2015 \\
\text { (53) }\end{array}$ & Overt & NS & $\begin{array}{l}\text { Previous } \\
\text { diagnosis of } \\
\text { hypothyroidis } \\
m \text {, or use of } \\
\text { THR }\end{array}$ & $\begin{array}{l}\text { NASH } \\
\text { (Steatosis) }\end{array}$ & $\begin{array}{l}3.79 \\
(1.20- \\
11.1)\end{array}$ \\
\hline & $\begin{array}{l}\text { Bano, } 2016 \\
\text { (12) }\end{array}$ & Overt & NS & $\begin{array}{l}\text { Biochemical, } \\
\text { no thyroid } \\
\text { medications, } \\
\text { no thyroid }\end{array}$ & $\begin{array}{l}\text { NASH } \\
\text { (Non- } \\
\text { NASH) }\end{array}$ & $\begin{array}{l}6.64 \\
(1.04- \\
23.98)\end{array}$ \\
\hline
\end{tabular}




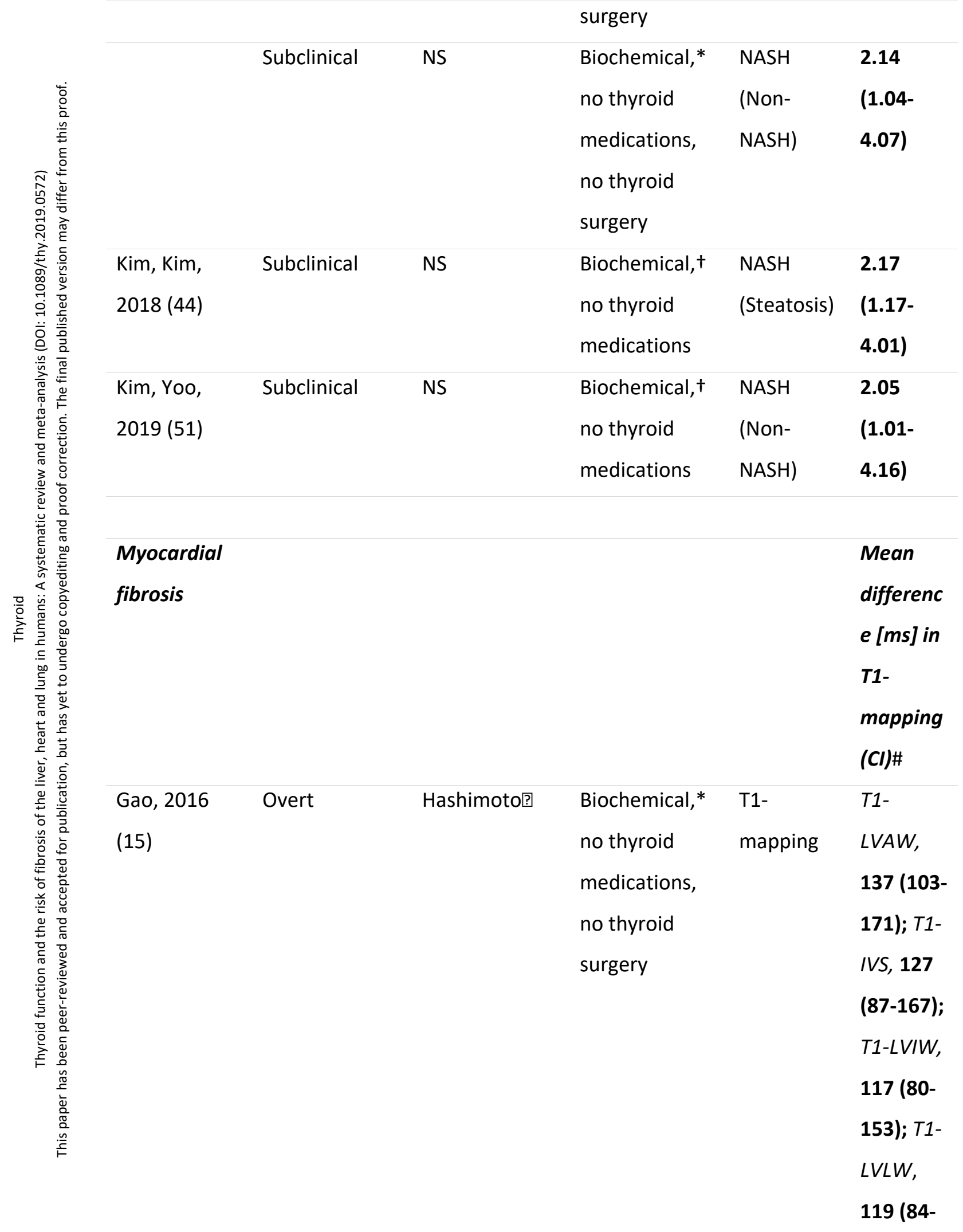


154)

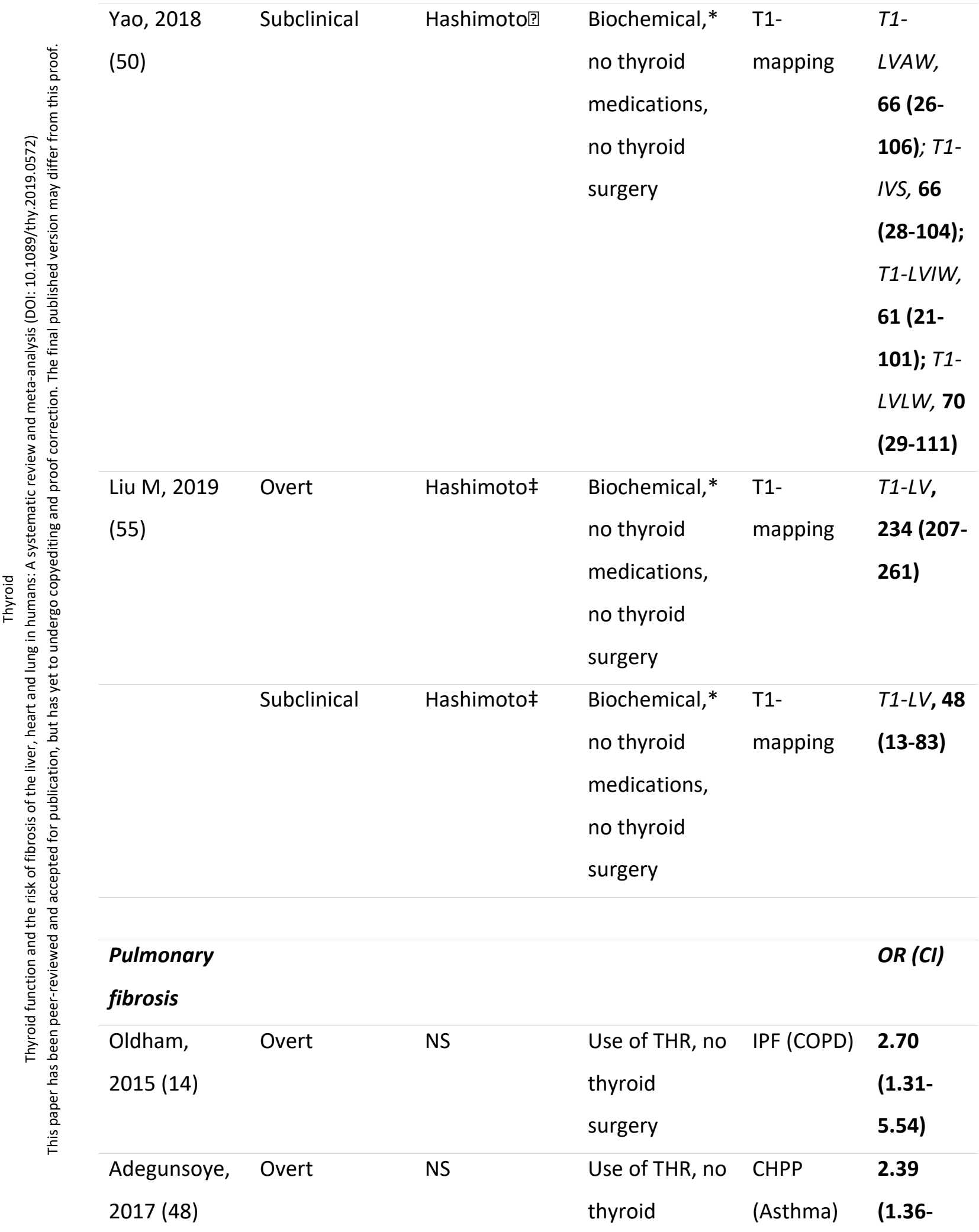




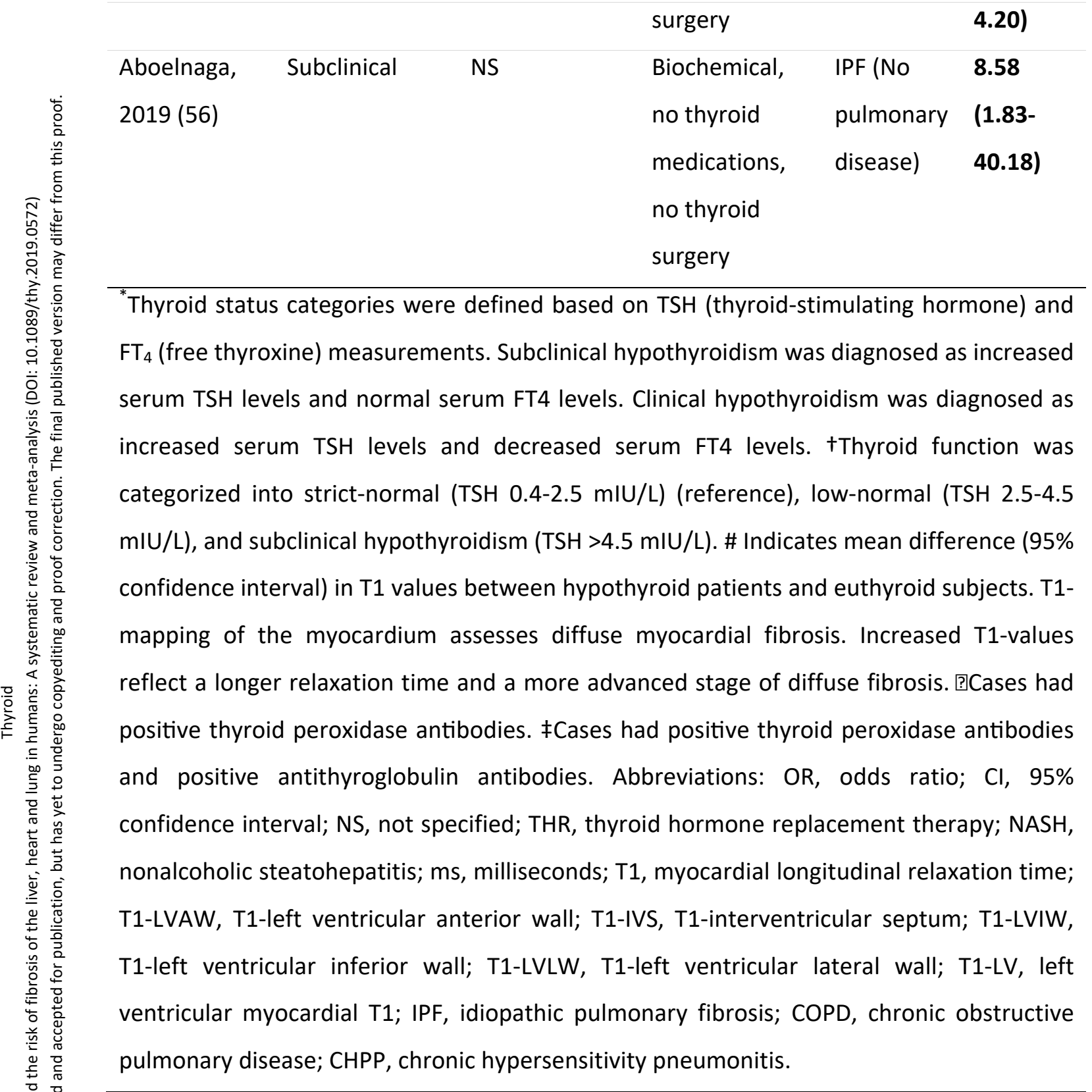


Table 3. Description of studies reporting on the association of thyroid parameters (TSH, $\mathrm{FT}_{4}, \mathrm{FT}_{3}$ ) with fibrosis of the liver, heart and lung ${ }^{\mathrm{a}}$

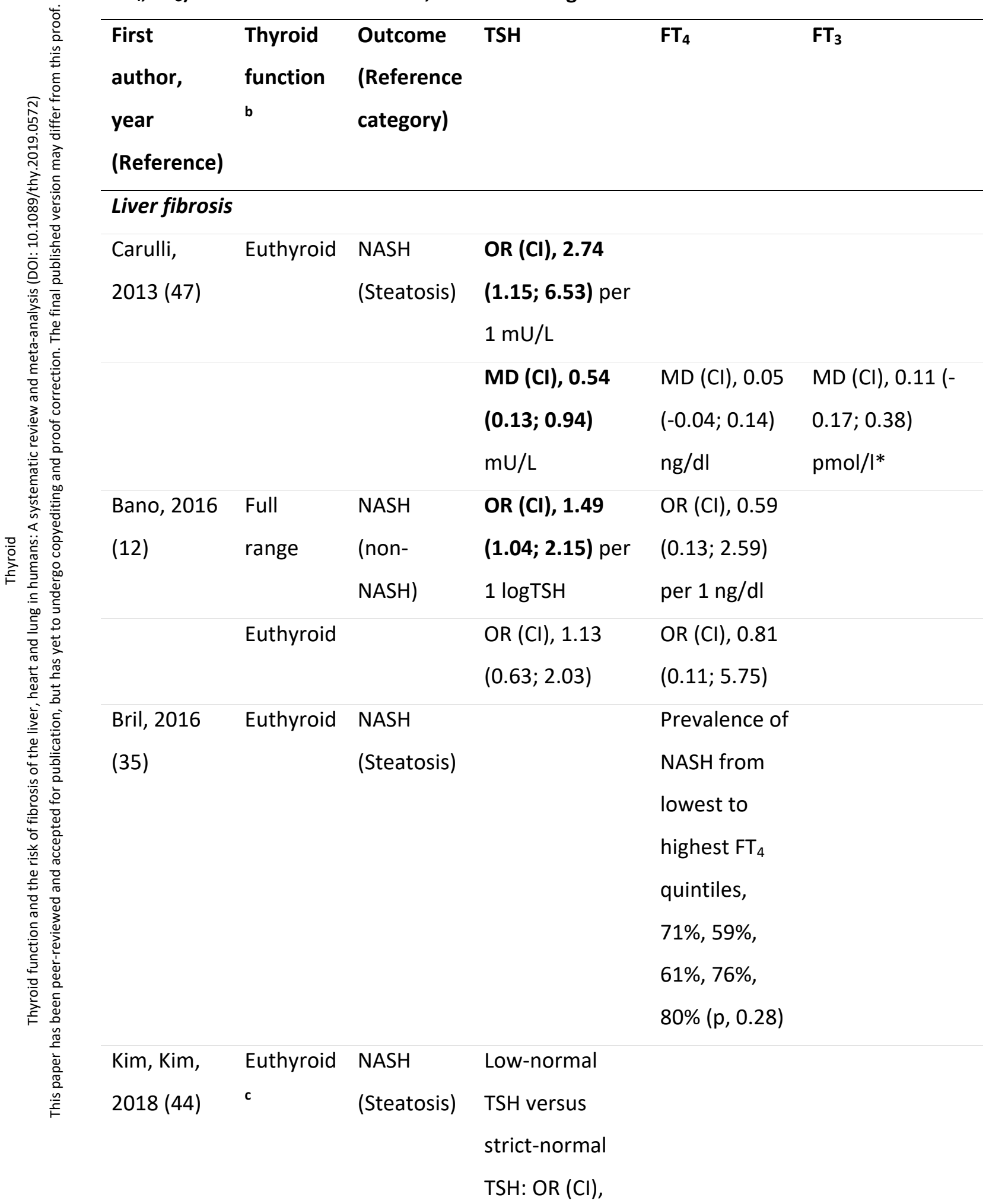




\section{$1.33(0.78 ; 2.24)$}

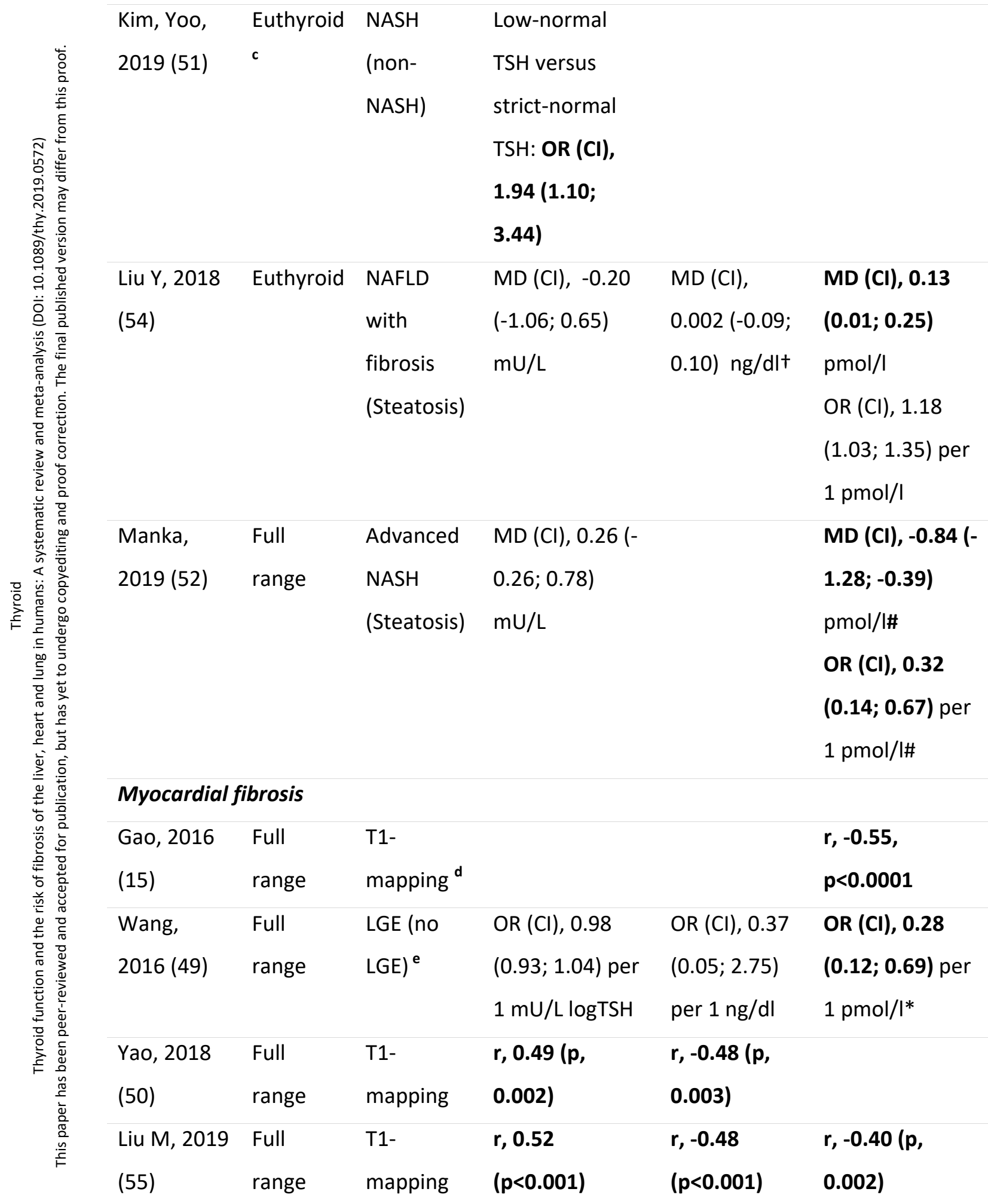


Pulmonary fibrosis

\begin{tabular}{|c|c|c|c|c|}
\hline \multirow[b]{2}{*}{ 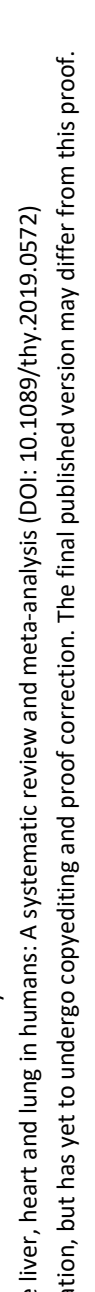 } & \multicolumn{2}{|c|}{$\begin{array}{ll}\text { Aboelnaga, } & \text { Full } \\
2019(56) & \text { range }\end{array}$} & $\begin{array}{ll}\text { IPF (No } & \mathrm{MD}(\mathrm{Cl}), 0.74 \\
\text { pulmonary } & (0.21 ; 1.27) \\
\text { disease) } & \mathrm{mU} / \mathrm{L}\end{array}$ & $\begin{array}{l}\mathrm{MD}(\mathrm{Cl}), 0.03 \\
(-0.17 ; 0.22) \\
\mathrm{ng} / \mathrm{dl}\end{array}$ \\
\hline & \multicolumn{4}{|r|}{$\begin{array}{l}\text { odds ratio for the association of } \\
\text { hyroid parameters between cases } \\
\text { late thyroid parameters with T1- } \\
\text { roughout the range of thyroid } \\
\text { euthyroid range or the full range } \\
\text { d into strict-normal (TSH } 0.4-2.5 \\
\text { d subclinical hypothyroidism (TSH } \\
\text { sses diffuse myocardial fibrosis. } \\
\text { a more advanced stage of diffuse } \\
\text { fibrosis. *Converted from pg/ml. } \\
\text { viations: TSH, thyroid-stimulating } \\
\text { thyronine; NASH, nonalcoholic } \\
\text { val; MD, mean difference; NAFLD, } \\
\text { Im enhancement; r, correlation } \\
\text { dial longitudinal relaxation time. }\end{array}$} \\
\hline
\end{tabular}




\begin{tabular}{|c|c|c|c|c|c|c|}
\hline \multirow{21}{*}{ 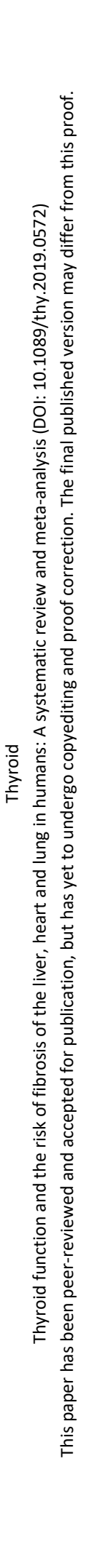 } & \multicolumn{6}{|c|}{ Table 4. Quality Assessment Scale } \\
\hline & $\begin{array}{l}\text { First author, year } \\
\text { (Reference) }\end{array}$ & $\begin{array}{l}\text { Selection } \\
\text { (maximum } 4 \\
\text { stars) }\end{array}$ & $\begin{array}{l}\text { Comparability } \\
\text { (maximum } 2 \\
\text { stars) }\end{array}$ & $\begin{array}{l}\text { Exposure or } \\
\text { outcome } \\
\text { (maximum } 3 \\
\text { stars) }\end{array}$ & $\begin{array}{l}\text { Total } \\
\text { number } \\
\text { of stars }\end{array}$ & $\begin{array}{l}\text { Quality } \\
\text { rating }\end{array}$ \\
\hline & $\begin{array}{l}\text { Liangpunsakul, } 2003 \\
\text { (45) }\end{array}$ & $* * *$ & $* *$ & $*$ & $6 / 9$ & Poor \\
\hline & Mazo, 2011 (36) & $* * *$ & & $* * *$ & $6 / 9$ & Poor \\
\hline & Pagadala, 2012 (46) & $*$ & $* *$ & $* * *$ & $6 / 9$ & Poor \\
\hline & Carulli, 2013 (47) & $* *$ & $* *$ & $* * *$ & $7 / 9$ & Fair \\
\hline & Parikh, 2015 (53) & $* * *$ & $* *$ & $* * *$ & $8 / 9$ & Good \\
\hline & Bano, 2016 (12) & $* * * *$ & $* *$ & $* *$ & $8 / 9$ & Good \\
\hline & Bril, 2016 (35) & $* *$ & & $* * *$ & $5 / 9$ & Poor \\
\hline & Kim, Kim, 2018 (44) & $* *$ & $* *$ & $* * *$ & $7 / 9$ & Fair \\
\hline & Kim, Yoo, 2019 (51) & $* * *$ & $* *$ & $* *$ & $7 / 9$ & Good \\
\hline & Liu Y, 2018 (54) & $* * *$ & $* *$ & $* *$ & $7 / 9$ & Good \\
\hline & Manka, 2019 (52) & $* *$ & $*$ & $* *$ & $5 / 9$ & Fair \\
\hline & Gao, 2016 (15) & $*$ & $*$ & $* * *$ & $5 / 9$ & Poor \\
\hline & Wang, 2016 (49) & $*$ & $* *$ & $* * *$ & $6 / 9$ & Poor \\
\hline & Yao, 2018 (50) & $* *$ & $*$ & $* * *$ & $6 / 9$ & Fair \\
\hline & Liu M, 2019 (55) & $* *$ & $*$ & $* * *$ & $6 / 9$ & Fair \\
\hline & Oldham, 2015 (14) & $* *$ & $* *$ & $*$ & $5 / 9$ & Poor \\
\hline & $\begin{array}{l}\text { Adegunsoye, } 2017 \\
\text { (48) }\end{array}$ & $*$ & $* *$ & $* *$ & $5 / 9$ & Poor \\
\hline & $\begin{array}{l}\text { Aboelnaga, } 2019 \\
\text { (56) }\end{array}$ & $* *$ & $* *$ & $* *$ & $6 / 9$ & Fair \\
\hline & \multicolumn{6}{|c|}{$\begin{array}{l}\text { †The thresholds for converting the Newcastle-Ottawa Scale (NOS) scores into the Agency } \\
\text { for Healthcare Research and Quality (AHRQ) standards were: (I) Good quality: } 3 \text { or } 4 \text { stars }\end{array}$} \\
\hline
\end{tabular}


stars in the comparability domain AND 2 or 3 stars in the exposure/outcome domain. (III) Poor quality: 0 or 1 star in the selection domain OR 0 star in the comparability domain OR or 1 stars in the exposure/outcome domain. 


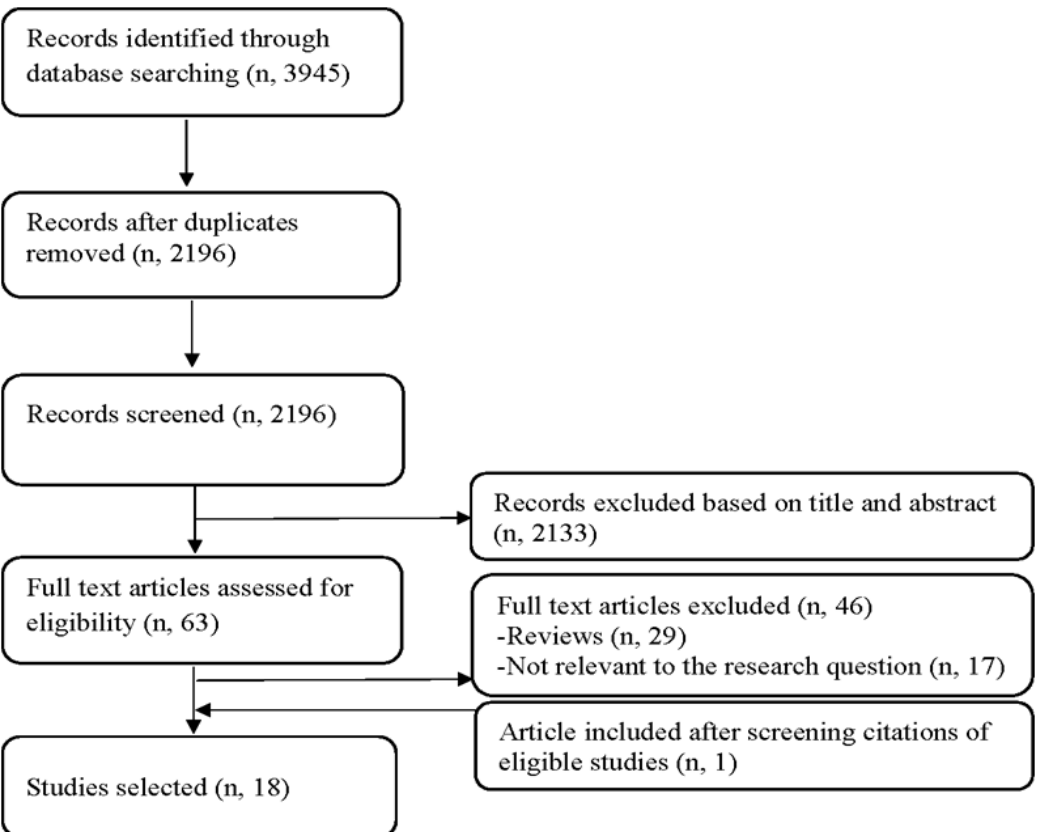

Figure 1. Flowchart for study inclusion, adapted from the PRISMA statement 
Page 39 of 53

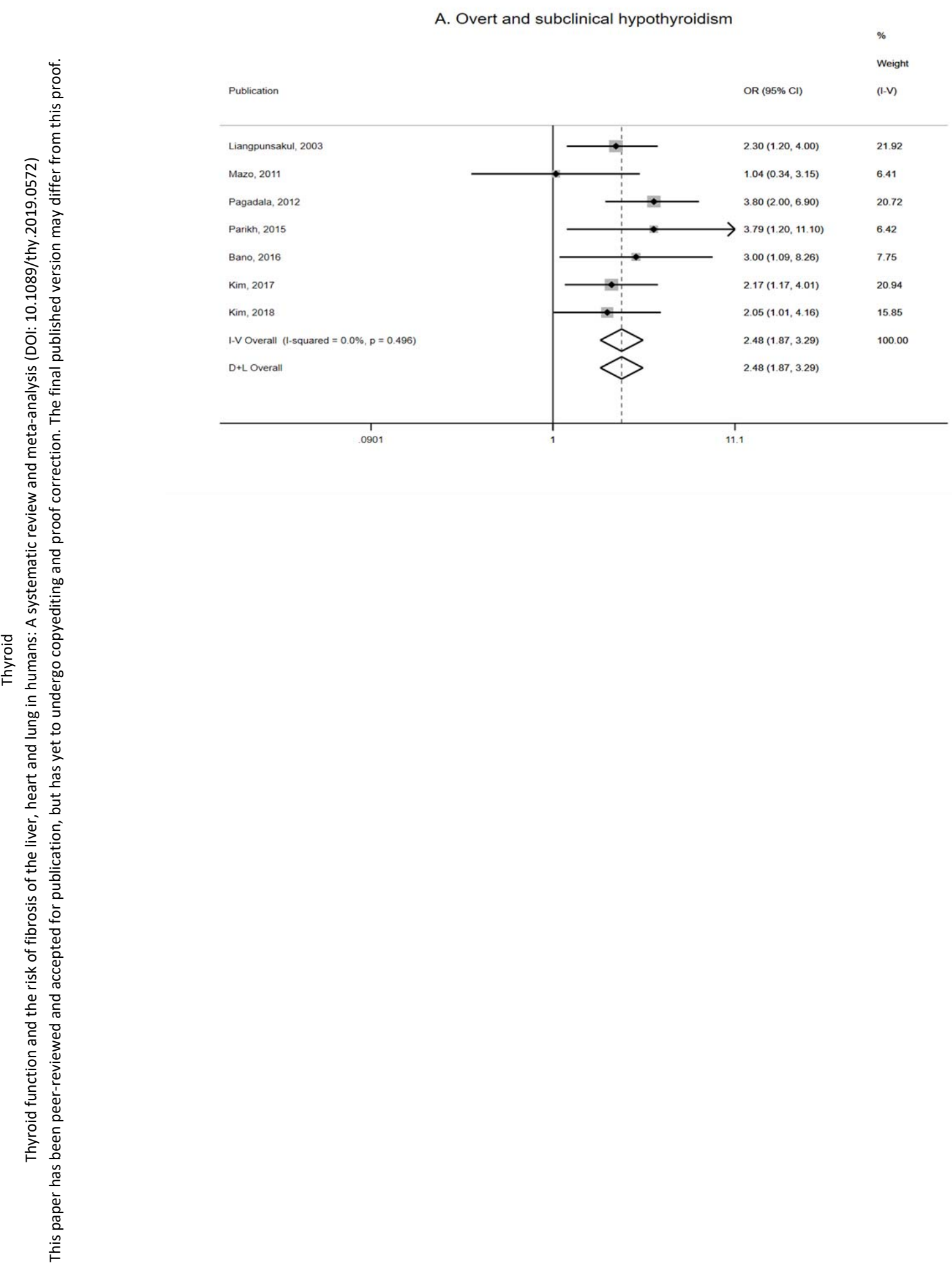


Page $\mathbf{4 0}$ of $\mathbf{5 3}$

B. Overt hypothyroidism

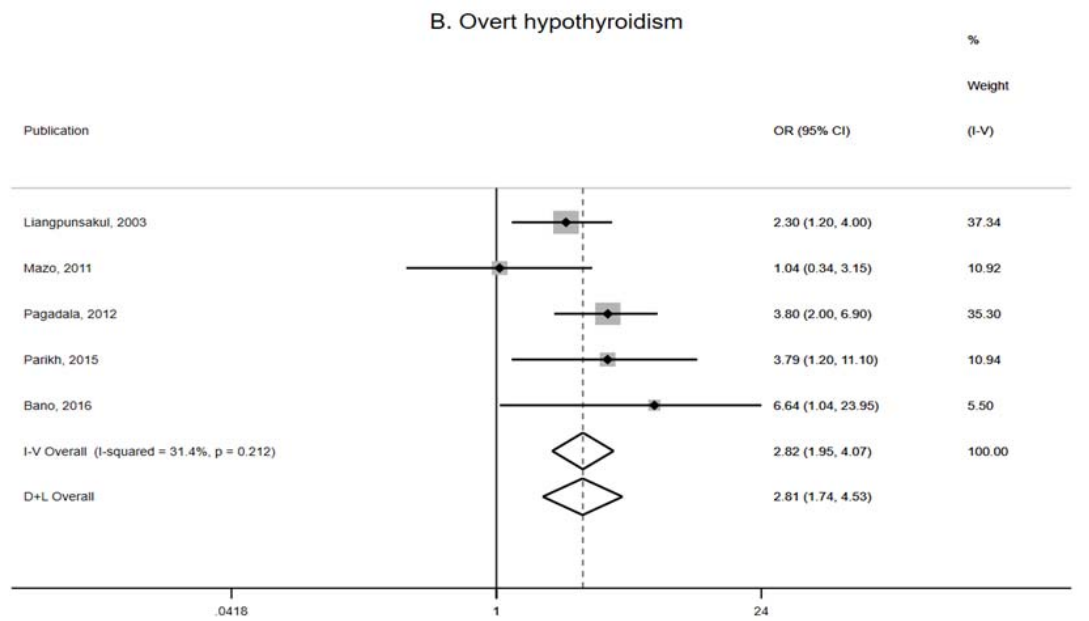




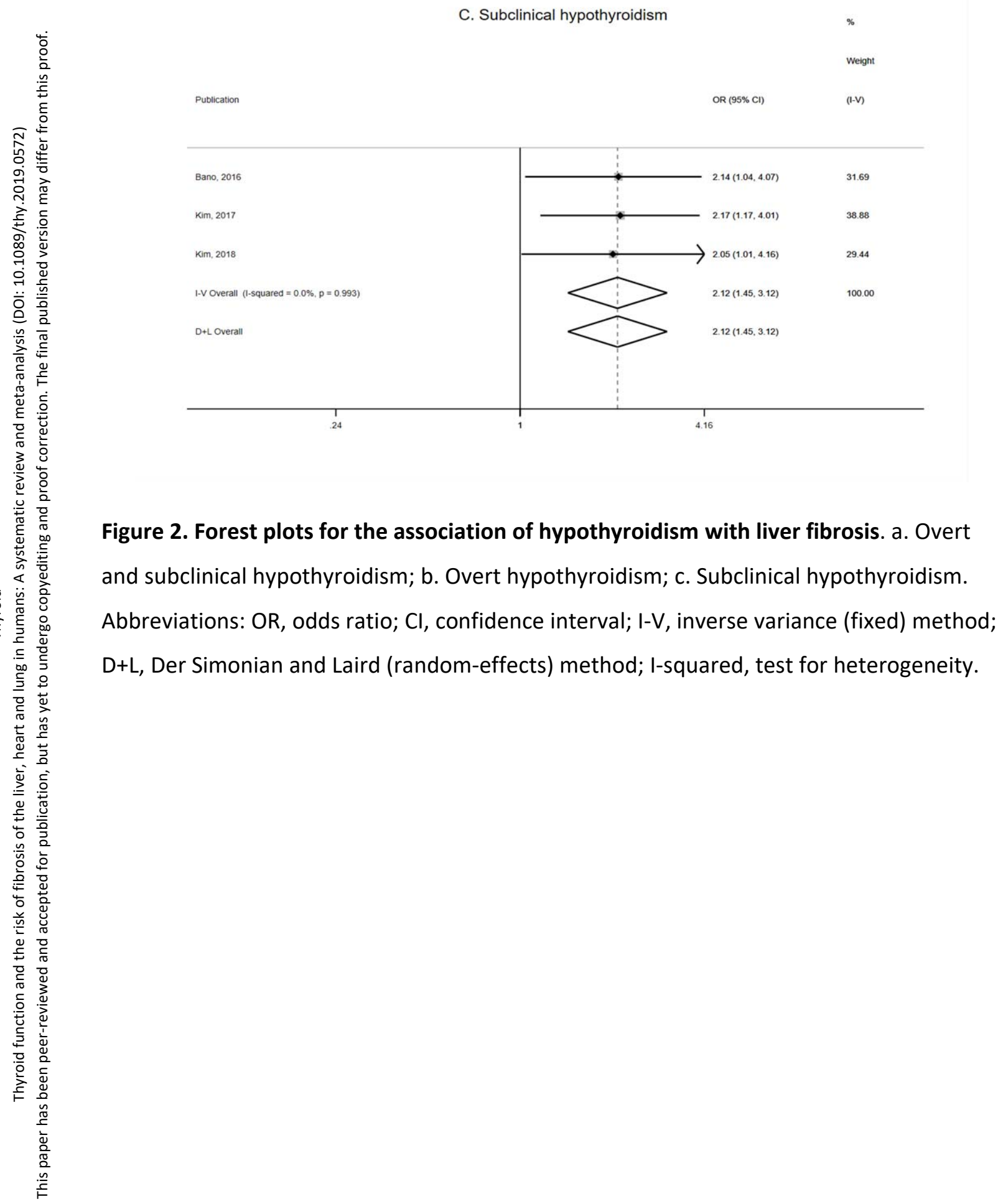


SUPPLEMENTAL MATERIAL

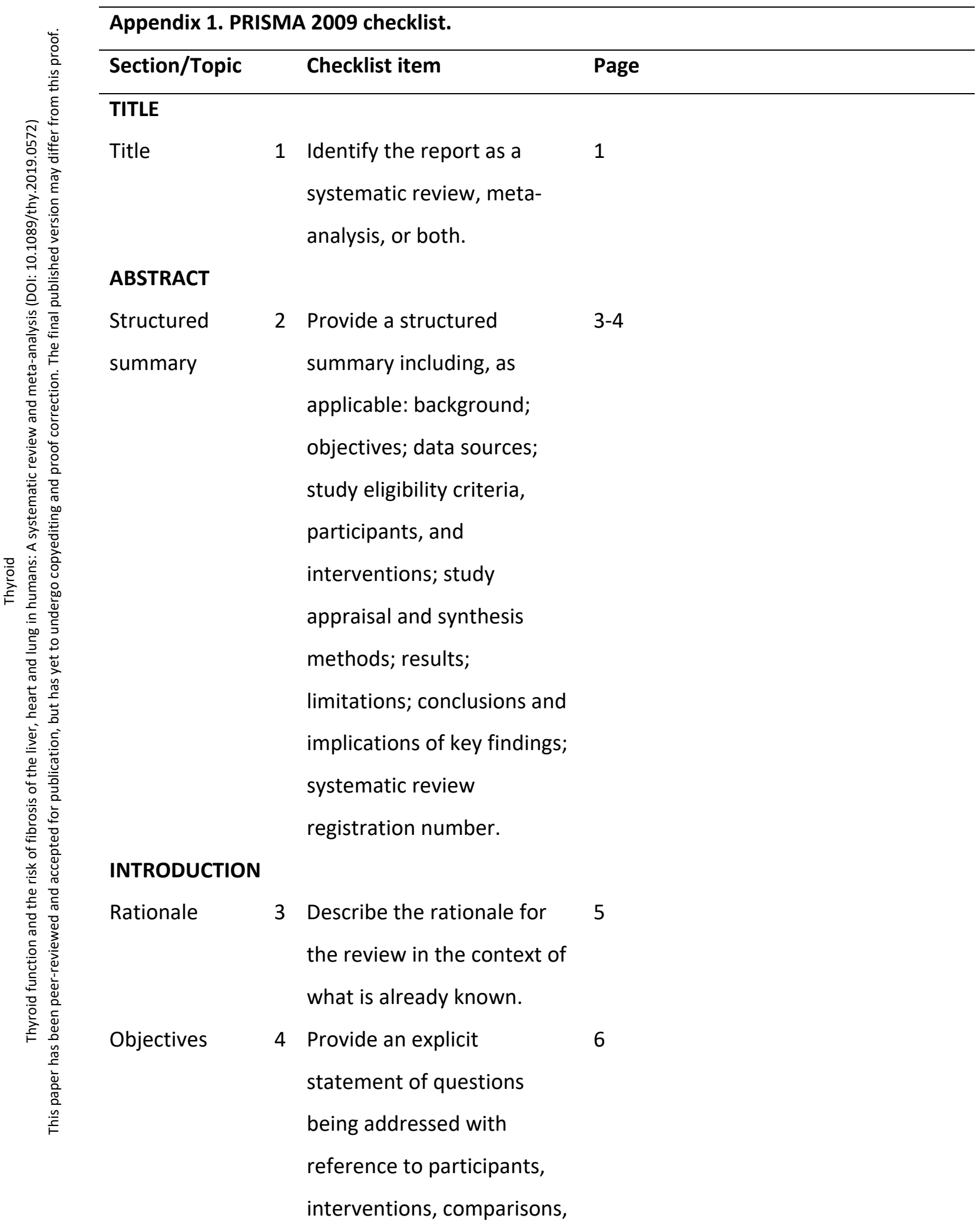


outcomes, and study design

(PICOS).

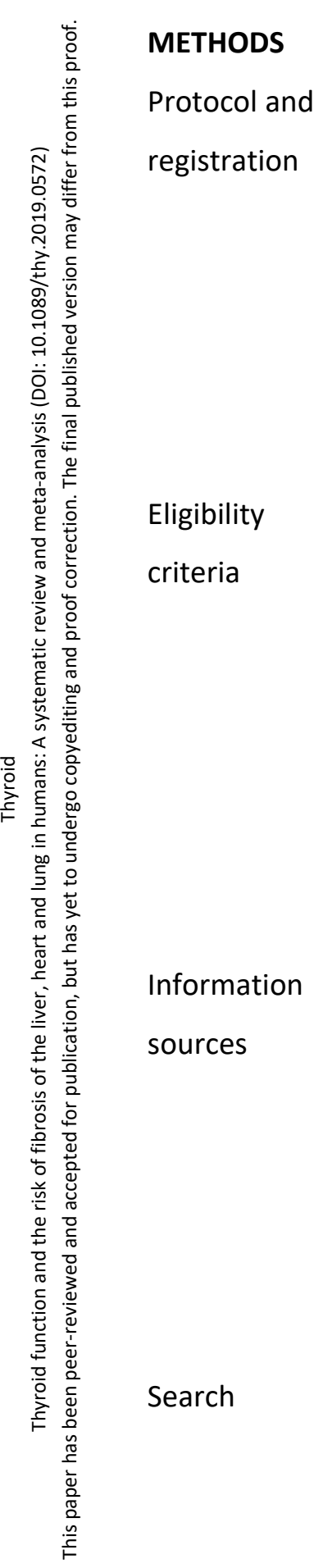

5 Indicate if a review protocol

https://boris.unibe.ch/132182/;

exists, if and where it can

https://www.crd.york.ac.uk/PROSPERO

be accessed (e.g., Web

Registration number:

address), and, if available,

CRD42019142703

provide registration

information including

registration number.

6 Specify study characteristics

7

(e.g., PICOS, length of

follow-up) and report

characteristics (e.g., years

considered, language,

publication status) used as

criteria for eligibility, giving

rationale.

7 Describe all information

6-7

sources (e.g., databases

with dates of coverage,

contact with study authors

to identify additional

studies) in the search and

date last searched.

8 Present full electronic

6-7, Appendix 2

search strategy for at least

one database, including any

limits used, such that it

could be repeated. 


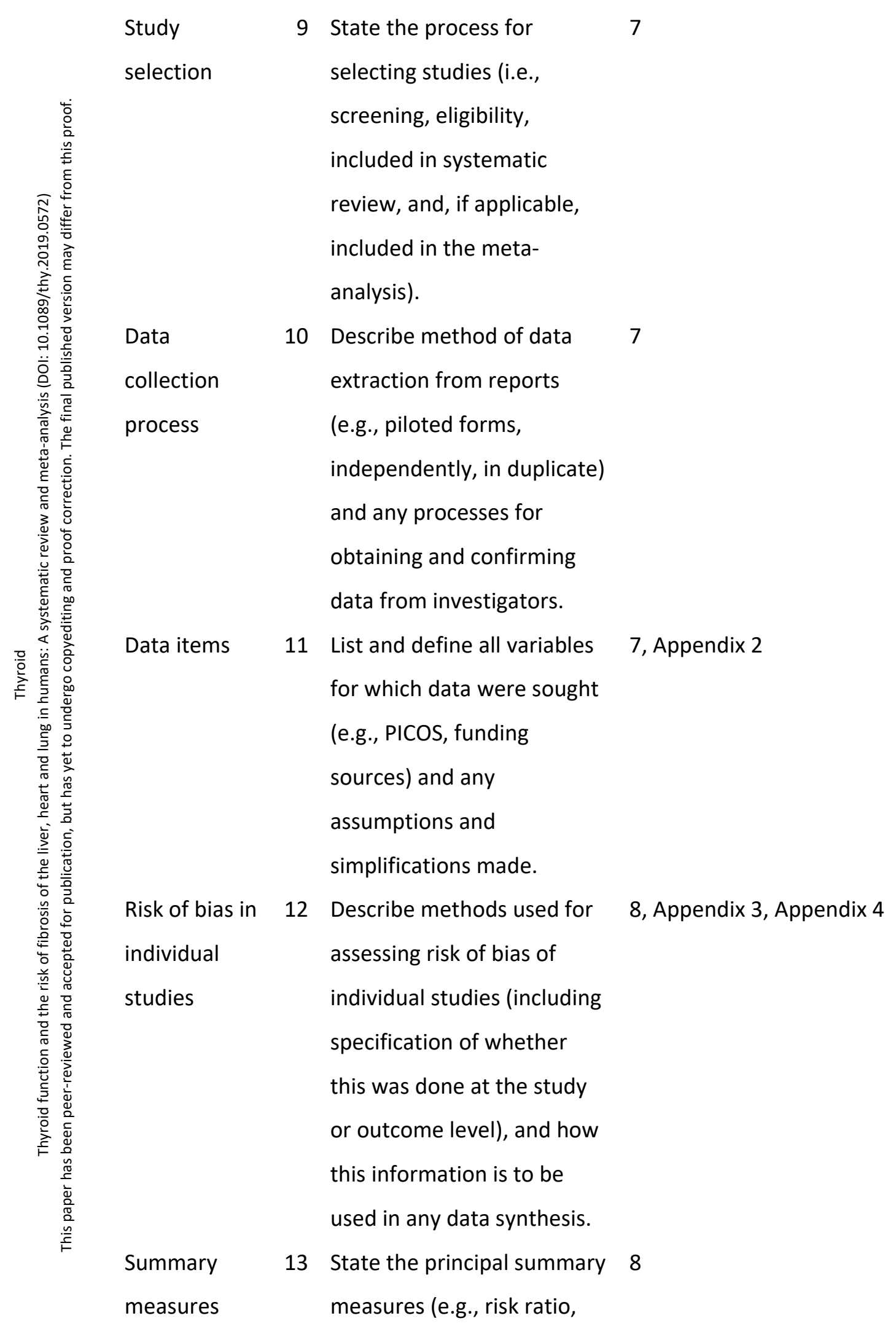


difference in means).

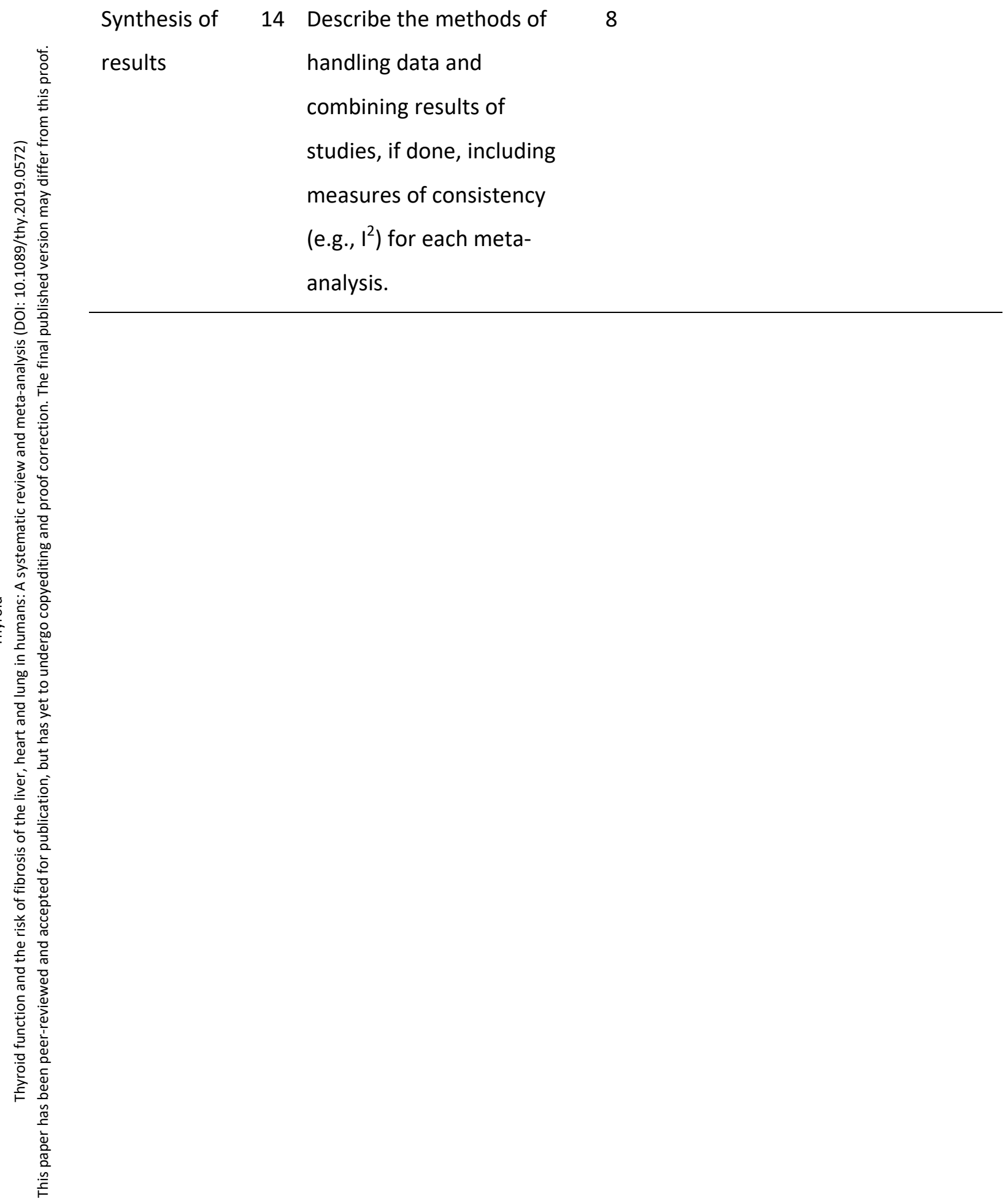


Appendix 1 (continued). PRISMA 2009 Checklist.

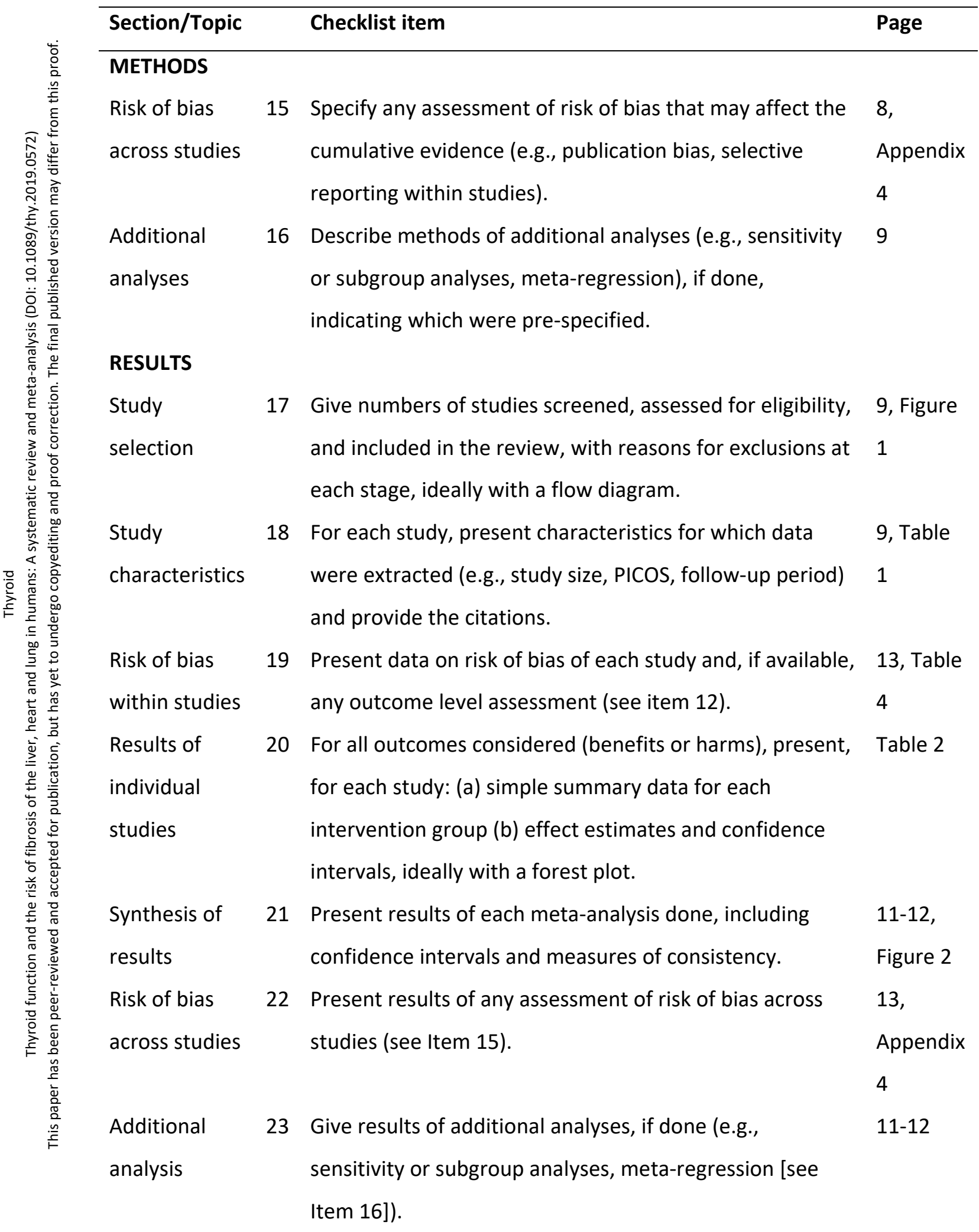




\section{DISCUSSION}

Summary of 24 Summarize the main findings including the strength of 13

evidence for each main outcome; consider their

relevance to key groups (e.g., healthcare providers, users, and policy makers).

\section{FUNDING}

Funding

27 Describe sources of funding for the systematic review and other support (e.g., supply of data); role of funders for the systematic review.

Moher D, Liberati A, Tetzlaff J, Altman DG, The PRISMA Group (2009). Preferred Reporting Items for Systematic Reviews and Meta-Analyses: The PRISMA Statement. PLoS Med 6(6): e1000097. doi:10.1371/journal.pmed1000097 


\section{Appendix 2. Supplemental information on Search strategy}

\section{Search in Pubmed}

(((Thyroid*[Title/Abstract] OR hyperthyro*[Title/Abstract] OR Hypothyro* [Title/Abstract]

OR thyronine* [Title/Abstract] OR Hashimoto[Title/Abstract] OR thyroid-stimulating hormone [Title/Abstract] OR "free thyroxine"[Title/Abstract] OR Graves[Title/Abstract] OR thyrotropin[Title/Abstract] OR deiodinase[Title/Abstract] OR triiodothyronine[Title/Abstract] OR myxedema[Title/Abstract] OR thyrotoxicosis[Title/Abstract] OR hyperthyroxinemia [Title/Abstract])) AND (Fibrosis[Title/Abstract] OR fibrotic[Title/Abstract] OR fibrosing[Title/Abstract] OR fibroblast[Title/Abstract] OR “non-alcoholic steatohepatitis"[Title/Abstract] OR "nonalcoholic steatohepatitis"[Title/Abstract])) AND (Heart [Title/Abstract] or cardiac [Title/Abstract] or cardiovascular[Title/Abstract] or lung [Title/Abstract] or pulmonary [Title/Abstract] or liver [Title/Abstract] or hepatic[Title/Abstract] or endocardium [Title/Abstract] or myocardium [Title/Abstract] or pericardium[Title/Abstract]) Search in Medline Ovid ((exp thyroid gland/ or hyperthyroxinemia/ or hyperthyroidism/ or hypothyroidism/ or thyroid function tests/ or thyroxine/ or thyroid hormones/ or thyrotropin/ or thyroxine/) OR (Thyroid* or hyperthyro* or Hypothyro* or free thyroxine or thyroid-stimulating hormone or Graves or thyrotropin or thyroxin or deiodinase or hashimoto or triiodothyronine or thyronine* or myxedema or thyrotoxicosis or hyperthyroxinemia).ab,ti.) AND ((Fibrotic or fibrosis or nonalcoholic steatohepatitis or nonalcoholic steatohepatitis or fibrosing).ab,ti. OR fibroblast.mp or fibrosis/ or exp pulmonary fibrosis/ or exp endomyocardial fibrosis/ or idiopathic pulmonary fibrosis/) AND (Heart or cardiac or endocardium or myocardium or pericardium or lung or pulmonary or liver or hepatic or cardiovascular).ab,ti. NOT (congress or editorial or guideline or letter or news or Published Erratum or conference or comment).pt.

Search in Embase Ovid ((exp thyroid gland/ or exp thyroid disease/ or exp thyroxine/ or exp thyroid function/ or thyroid hormone/ 
or thyrotropin/ or thyroxine/ or exp thyroid hormone blood level/ or exp thyroid gland examination/) or (Thyroid* or hyperthyro* or Hypothyro* or free thyroxine or Graves or thyrotropin or thyroxin or deiodinase or hashimoto or triiodothyronine or thyronine* or myxedema or thyrotoxicosis or hyperthyroxinemia).ab,ti. ) AND ((Fibrotic or fibrosis or non-alcoholic steatohepatitis or nonalcoholic steatohepatitis or fibroblast).ab,ti. Or (exp fibrosing alveolitis/ or exp fibrosing interstitial pneumonia/ or exp heart muscle fibrosis/ or exp liver fibrosis/ or exp lung fibrosis/)) AND ((Heart or cardiac or endocardium or myocardium or pericardium or lung or pulmonary or liver or hepatic or cardiovascular).ab,ti.) NOT (Editorial or Letter or Note or Erratum or Conference Paper or Conference Abstract or Conference Review).pt.

Search in Web-of-Science

(TS=(Thyroid* or hyperthyro* or Hypothyro* or "free thyroxine" or thyroid-stimulating hormone or Graves or thyrotropin or deiodinase or triiodothyronine or myxedema or thyrotoxicosis or hyperthyroxinemia or thyronine* or hashimoto)) AND (TS=(Fibrosis or fibrotic or fibroblast or non-alcoholic steatohepatitis or nonalcoholic steatohepatitis or fibrosing)) AND (TS=(Heart OR cardiovascular or cardiac OR endocardium OR myocardium OR pericardium OR lung or pulmonary OR liver OR hepatic)) AND DOCUMENT TYPES: (Article)

\section{Appendix 3. Quality Assessment Scale for included studies}

\section{Appendix 3a. Newcastle-Ottawa Quality Assessment Scale for case-control studies} Selection (max 4 stars)

1) Is the case definition adequate?

a. yes, with independent validation*

b. yes, eg, record linkage or based on self-reports

c. no description

2) Representativeness of the cases

a. consecutive or obviously representative series of cases*

b. potential for selection biases or not stated

3) Selection of controls

a. community controls*

b. hospital controls 
c. no description

4) Definition of controls

a. no history of disease (end point)*

b. no description of source

\section{Comparability (max 2 stars)}

1) Comparability of cases and controls on the basis of the design or analysis

a. study controls for the most important factors*

b. study controls for any additional factor**

\section{Exposure (max 3 stars)}

1) Ascertainment of the exposure

a. secure record (eg, surgical records)*

b. structured interview where blind to case/control status*

c. interview not blinded to case/control status

d. written self-report or medical record only

e. no description

2) Same method of ascertainment for cases and controls
a. yes*
b. no

3) Non-response rate
a. same rate for both groups*
b. non-respondents described
c. rate different and no designation

Appendix 3b. Adapted Scale from the Newcastle-Ottawa Quality Assessment Scale for cohort studies

\section{Selection (max 4 stars)}

1) Representativeness of the exposed cohort

a. Truly representative of the average in the target population (all subjects or random sampling)*

b. Somewhat representative of the average in the target population (nonrandom sampling)*

c. Selected group of users 
d. No description of the derivation of the cohort

2) Sample size

a. Justified and satisfactory*

b. Not satisfied

3) Ascertainment of the exposure (risk factor)

a. Secure record (eg, medical records)*

b. Structured interview*

c. Written self-report

d. No description of the measurement tool

4) Non-respondents

a. Comparability between respondents and non-respondents characteristics is established, and the response rate is satisfactory*

b. The response rate is unsatisfactory, or the comparability between respondents and non-respondents is unsatisfactory

c. No description of the response rate or the characteristics of the respondents and the non-respondents

\section{Comparability (max 2 stars)}

1) The subjects in the different outcome groups are comparable, based on the study design or analysis. Confounding factors are controlled.
a. Study controls for the most important factors (age, sex)*
b. Study controls for additional relevant factors**
c. Inadequate degree of control

\section{Outcome (max 3 stars)}

1) Assessment of the outcome
a. Independent or blind assessment stated in the paper, or confirmation of the outcome by reference to secure records (eg, X-rays, medical records)**
b. Record linkage (eg, identified through ICD codes on database records)**
c. Self-report (ie, no reference to original medical records or X-rays to confirm the outcome)*
d. No description 
Page 52 of 53

52

\section{2) Statistical test}

a. The statistical test used to analyze the data is clearly described and appropriate, and the measurement of the association is presented, including the probability level ( $p$-value)*

b. The statistical test is not appropriate, not described or incomplete. 
